\title{
The larval morphology and the effects of sound frequencies on the settlement behaviour of the biofouling Bryozoan: Watersipora subatra
}

By Renae Nicole McLachlan

\begin{abstract}
A thesis
submitted to the Victoria University of Wellington

in fulfilment of the requirements for the degree of

Masters' by thesis
\end{abstract}




\section{Abstract}

Biofouling is a global issue, it is an ongoing expense for the maritime industry, billions of dollars are spent annually due to increased fuel consumption, research, maintenance and upkeep. The toxicity of anti-fouling paints is also a serious issue for the marine environment, because of the non-selective nature of the toxins they contain, they also affect non-target species, potentially harming local ecosystems. Biofouling acts as a vector for invasive species, allowing these species to spread world-wide, establish themselves in new ecosystems and potentially alter the biodiversity of the native flora and fauna. These issues with biofouling have seen an increase in research into the prevention of settlement of unwanted organisms on ship hulls; especially biofriendly, alternative options to toxic anti-fouling paints. A holistic approach to researching fouling species is vital in reducing and preventing biofouling, and with the increase in human activity in the marine environment, the effects of anthropogenic sounds on marine organisms is of growing interest. The potential effect of vessel noise on the larvae of bryozoan species has yet to be explored even though the Phylum Bryozoa is notorious for biofouling species. The morphology of larvae is also important in understanding the ecology of marine species, as various factors that influence the larval stage of a species can have latent effects in other life stages. Insight into the morphology of fouling larvae is important in understanding their life histories to develop more robust antifouling methods. Bryozoan larvae have a diverse range of morphological features to increase their survivability; a number of structures have been identified in aiding locomotion, phototaxis behaviour, suitable habitat exploration and metamorphosis. There is still a lot of speculation over the purpose of different structures and whether they have the potential to be used in other behaviours (such as auditory capabilities). This thesis focuses on the biofouling bryozoan species, Watersipora subatra, and examines their larval morphology and behaviour to better understand their early ecology and identify potential structures with auditory capabilities. SEM images of the larvae were used to identify a number of sensory organs that could potentially detect sound. A sound experiment was also conducted to test whether their larvae respond to different frequency levels $(100 \mathrm{~Hz}, 500 \mathrm{~Hz}$ and $1000 \mathrm{~Hz})$. There was no significant difference in the settlement rate at the end of a 24 -hour period between the different treatments. 
However, the larvae exposed to the lower frequency $(100 \mathrm{~Hz})$ tended to be slower at settling in the initial 8 hours of the experiment, which is the optimal time to settle to increase postsettlement survivability. There is the potential for the larvae of bryozoan species to respond to sound frequencies, although more research is needed to fully elucidate their potential to sense sound and to potentially aid in developing a biofriendly, preventative solution to biofouling. 


\section{Acknowledgements}

I would like to thank everyone that has persisted with me and this project. I would personally like to thank Ken Ryan, my supervisor at Victoria University, whose advice and mentoring was invaluable; my supervisors at NIWA, Serena Wilkens and Dennis Gordon, who were enthusiastic and excited about the project and were always happy to help. For giving me the opportunity and ability to carry out and complete this project I want to thank Victoria University of Wellington and NIWA. VUCEL and the lab technicians, thank you for allowing me to work in the labs. I want to acknowledge the NIWA invertebrate collections team as well as Daniel Leduc (NIWA), who welcomed me into their labs and allowed me to use their equipment. I thank Auckland University and Prof. Andrew Jeffs for allowing me use of your equipment and sound recordings.

I want to thank Madeline Cooper for always accompanying me on collections, rain or shine. Thank you to my friends and family, who were always supportive and believed in me and a special mention to Harrison Spark for his constant emotional support. For my mum and dad, who sacrificed a lot for me to be where I am, I want to thank you for your unwavering belief in me and for making me the woman I am today. Lastly my husband, Steven McLachlan, I want to thank you for your unconditional love and support throughout everything, and for always inspiring me to better myself, without you I would never have had the courage to go back to university. I would like to dedicate this thesis to my nephew Samuel Kenny. 


\section{Contents}

Abstract

Acknowledgements

iii

Table of Figures

vii

Table of Tables

viii

Abbreviations

ix

Terminology

$x$

Chapter One: General Introduction

1.1 Introduction 1

1.2 Antifouling Techniques 3

1.2.1 Antifouling in Aquaculture 4

1.2.2 Coatings 5

1.2.3 Alternative Antifouling Techniques 8

$\begin{array}{lll}1.3 & \text { Sound } & 10\end{array}$

1.3.1 Natural Underwater Sound 10

1.3.2 Anthropogenic Underwater Sound 12 
1.4.1 Biofouling Bryozoa 14

1.4.2 Bryozoa Larval Behaviour 14

1.5 Proposed Aims and Hypotheses 15

Chapter Two: Scanning electron microscopy of Watersipora subatra larval morphology

2.1 Introduction

2.2 Methods

2.2.1 Adult collection and larval release 23

2.2.2 Scanning Electron Microscope Preparation 23

2.2.3 Scanning Electron Microscopy 25

2.3 Results: Larval behaviour and morphology 26

2.4 Discussion

Chapter 3: The effects of sound frequencies on the settlement behaviour of Watersipora subatra larvae

3.1 Introduction

3.2 Methods 
3.2.1 Larval collection and sound experiment

3.2.2 Data analyses

3.3 Results

3.4 Discussion

Chapter 4: Overview, discussion and future directions

4.1 General overview

References

Appendices

Appendix A: SEM images

71

Appendix B: Graphs and R output

74 


\section{Table of Figures}

2.1 Free-swimming Watersipora subatra larvae (C-D: SEM images).

2.2 SEM images of the ciliated coronal band of Watersipora subatra larvae.

2.3 SEM images of the supracoronal and infracoronal cells of Watersipora subatra larvae.

2.4 SEM images of eyespots on Watersipora subatra larvae.

2.5 SEM image of a flagellar tuft on a Watersipora subatra larva.

2.6 SEM images of a vibratile plume on Watersipora subatra larva.

2.7 SEM images of Watersipora subatra larvae undergoing cleaving.

2.8 settled Watersipora subatra larvae (B: SEM image).

3.1 Satellite image of Chaffers marina, Wellington.

3.2 $6 \times 4$ visually and acoustically transparent well plate

3.3 Water bath layout of sound experiment

3.4 Boxplot of settlement time (Hours) of Watersipora s. within each water bath for each treatment. A: Silent control; B: Treatment one; C: Treatment two; D: Treatment three.

3.5 Bar graph of mean settlement times (h) for Watersipora s. larvae in each treatment. T1: Treatment one; T2: Treatment two; T3: Treatment three.

3.6 Proportion (\%) of settling Watersipora s. larvae over time (h) for each Treatment. T1: Treatment one; T2: Treatment two; T3: Treatment three. 


\section{Table of tables}

3.1 Kruskal-Wallis comparisons of ranks for a difference in the distribution of median settlement among the replicate water baths within the same treatment.

3.2 Shapiro-Wilk's test for normality: W-statistic, $\alpha$ and $p$-value for data within each treatment and the pooled data set.

3.3 The Anderson-Darling test for normality: A-D-statistic, $\alpha$ and $p$-value for data within each treatment and the pooled data set.

3.4 Summary of settled and unsettled larvae in each treatment at the of the 24-hour experiment period.

3.5 Summary of settled and unsettled larvae in each treatment at the of the 24-hour experiment period. 
TBT Trybutyltin

APP Antifouling paint particles

CPD Critical point drying

SEM Scanning electron microscope

REML Restricted Maximum Likelihood criterion

ML Maximum Likelihood criterion 


\section{Terminology}

Ancestrula: The original zooid of a colony, generated by the catastrophic metamorphosis of a larva; typically, it differs slightly in size and morphology from other zooids within a colony. Biocides: a poisonous substance, typically a pesticide.

Biofilm: a thin but robust layer of mucilage adhering to a solid surface and containing a community of bacteria and other microorganisms.

Catastrophic metamorphosis: The process a larva undergoes once it has settled on a substrate to become the ancestrula zooid. The process is very rapid.

Lecithotrophic: A form of development in which the embryo receives no nutrition other than the yolk originally contained within its egg.

Organotin: of, concerned with, or being an organic compound with one or more tin atoms in its molecules: used as a pesticide, hitherto considered to decompose safely, now found to be toxic in the food chain

Planktotrophic: meaning "feeding on plankton" refers to development via a larva that must feed in the plankton in order to develop to metamorphosis. Species with planktotrophic development produce many small energy-poor eggs with adequate nutrient reserves for the development of a feeding larva

Soundscape: a piece of music considered in terms of its component sounds.

Tentacle crown: The tentaculated feeding apparatus of Bryozoans

Zooid: Is an individual within a colony, one of the physiologically linked, repeating units of a colony; either a reproductive unit and/or a feeding unit or a number of other polymorphs. 


\section{Chapter One: General Introduction}

\subsection{Introduction}

Biofouling can be summarised as the settlement of unwanted organisms such as sessile invertebrates, algae and bacteria on submerged surfaces and this can have adverse effects on vessels, aquaculture infrastructure, filters and any submerged equipment (Gordon \& Matwatari, 1992; Rosenhahn et al., 2010). Biofouling also affects native ecosystems and the economy via increased fuel consumption, thereby increasing transport costs and maintenance (Piola \& McDonald, 2012; Sams \& Keough, 2012).

The expansion of the global shipping industry has allowed invasive species to be transported around the globe by fouling vessel hulls (Bax et al., 2003; Inglis et al., 2012; Piola \& McDonald, 2012; Sams \& Keough, 2012). In North America, commercial vessels have been responsible for $44-78 \%$ of initial invasions of nonindigenous species with $52-82 \%$ of these species being associated with biofouling on vessels in the last 30 years (Ruiz et al., 2015). Smaller recreational vessels can also act as vectors for invasive marine species and can be responsible for the regional spread of invasive species as they tend to have fewer restrictions on them compared to commercial vessels (Lacoursiere-Roussel et al., 2012; Brine et al., 2013; Roche et al., 2015; Kauano et al., 2017).

Small recreational vessels have been used in predictive models to determine the spread of biofouling species (Lacoursiere-Roussel et al., 2012). Furthermore, recreational vessels on swing moorings had higher biofouling levels compared to vessels attached to berths; the vessels that docked to the swing moorings were typically slower moving in the water, therefore, unlikely to displace fouling organisms thus increasing their potential to spread invasive species over a wider area via reproduction (Brine et al., 2013). Recreational vessels typically act as a secondary stage of the spread of invasive species as they are not monitored to the same level as commercial vessels. Typically, upkeep and maintenance on these vessels are inconsistent, and their excursions are sporadic, so they have the potential to establish higher levels of fouling when moored, especially if the antifouling methods have 
lapsed; and are then able to go to locations that would normally be isolated from commercial vessels, allowing the secondary spread of invasive species (Roche et al., 2015; Kauano et al., 2017).

Aquaculture is a growing industry with the World Bank 2013 Fish to 2030 report projecting $60 \%$ of fish consumed in 2030 will come from aquaculture. With this greater demand for food production, Waite et al. (2014) suggest that aquaculture will have to double its production at least to avoid exerting too much pressure on wild fisheries by 2050. With aquaculture developing into such a vital industry for sustainable food resources, issues arising from biofouling are becoming more evident and problematic. The type of setup being used typically will affect whether the cultivated species or the infrastructure are more greatly affected by fouling. Shellfish aquaculture is more affected by the physical damage of the stock caused by fouling; while finfish aquaculture is affected by infrastructure damage caused by fouling on the netting and cages. In bivalve aquaculture, the cost of biofouling control and removal represents up to $30 \%$ of the overall operational costs. The adverse effects of several toxic anti-fouling methods mean they are not often suitable for aquaculture as the chemicals used will also affect the cultured stock, so other non-lethal techniques need to be used. The products used to control of biofouling in aquaculture need to be carefully considered with regards to the local ecosystems and the rules and legislations surrounding biocides, as biocides can have detrimental effects on the cultured species and the surrounding environment. (Fitridge et al., 2012; Lacoste \& GaertnerMazouni, 2015).

Fitridge et al. (2012) found that shellfish aquaculture was affected by physical damage (burrowing), mechanical interference (overgrowth), biological competition (food, space and resources), increased drag (requires increased floats and maintenance) and environmental alteration (reduced water flow and changes in waste concentrations). In addition, fish aquaculture was affected by fouling on nets restricting water exchange (oxygen depletion), disease risk (fouling organisms harbouring pathogens), cage deformation and structural fatigue (added weight) (Fitridge et al., 2012).

The spread of invasive species poses a major threat to local ecosystems worldwide and is considered one of the biggest threats to native biodiversity (Hewitt et al., 2004; Hayden et al., 2009; Piola \& Conwell, 2010). Biofouling acts as a vector for invasive organisms and has 
facilitated the establishment of many foreign fauna and flora in ports and harbours worldwide, and several of these organisms have spread throughout near-by ecosystems (Piola \& McDonald, 2012). Continuous monitoring and offshore data collection devices are also affected by biofouling, and this can ultimately affect the accuracy of the data collected (Venkatesan et al., 2017).

Globally, biofouling is a major economic issue. Not only does it result in financial loss to many marine industries by creating resistance drag, thus increasing fuel consumption, but there is also the additional equipment costs associated with engine maintenance. The antifouling industry is a billion-dollar industry with preventative measures (anti-fouling paint) and active removals being very costly (Lacoste \& Gaertner-Mazouni, 2015). For example, the associated costs of biofouling cost the US Navy approximately USD\$56M annually over the entire fleet of 62 Arleigh Burke-class destroyers (DDG-51) (Schultz et al., 2011). The authors concluded that improvements of anti-fouling methods would substantially reduce the annual budget spent on biofouling and the savings would eventually cover the cost of research and implementation of new techniques. Similarly, the UK water industry spent £1.49M over a four-year period due to persistent foulers; with common, biofouling bryozoans being discovered growing on rapid gravity filters within these facilities reducing the effectiveness of the filter (Mant et al., 2011; Mant et al., 2013).

\subsection{Antifouling Techniques}

Ever since man has used vessels, biofouling organisms have presented an ever-growing problem. The use of various anti-fouling techniques dates back as far as 700 B.C., where copper sheathing was used; since then the technology had changed and improved until the mid-19 $19^{\text {th }}$ century when the use of toxic paints (mercury oxide, copper or silver) became popular mainly due to the ease of application. In the 1950s organometallic paints containing tributyltin (TBT) became very popular and were often used in conjunction with copper based paints (Almeida et al., 2007). However, due to the leaching properties common among toxic paints, most can have a devastating effect on marine ecosystems; an example of this is the population decline of a commercial oyster in France during the 1970s and 80s, high concentrations of TBT were found to cause shell deformities and drastically decrease reproduction (Alzieu, 2000; Nehring, 2001). Throughout recent decades there has been an 
increase in research on more bio-friendly, nontoxic solutions to biofouling, which has resulted in a more holistic approach and a comprehensive range of new techniques.

\subsubsection{Antifouling in Aquaculture}

Biofouling is responsible for several problems within the aquaculture industry, affecting both the cultured species and the infrastructure. Physical removal is an obvious choice for shellfish aquaculture however it can be stressful for the stock and is expensive as it requires much effort on a regular basis. One method of physical removal is immersing the shellfish into fresh water; it is inexpensive and environmentally friendly (Fitridge et al., 2012). However, it is not wholly effective, and prolonged exposure to fresh water has potential to stress the stock. Heat treatment is another option that is easy to apply and has a limited environmental impact although it is not effective against any heat-resistant organisms. A natural strategy used in shellfish aquaculture is simply avoiding recruitment by removing the stock from depths favoured by fouling organisms during their breeding seasons to reduce colonisation. Nevertheless, this approach is ineffective at removing preexisting fouling biomass and isn't successful in environments where fouling is constant (Fitridge et al., 2012; Sievers et al., 2014). Another natural strategy is biological control, where predators of known foulers can be introduced to control the populations. This may be effective within small-scale shellfish operations; however, many ecological factors (life cycle, ability to acclimate) would need to be considered when choosing a suitable predator to ensure the local ecosystem remains relatively unafflicted (Fitridge et al., 2012). Maintaining and containing predators over an extended period can be difficult and could require amendments to the culture techniques and it is also considered too tenuous for large-scale operations. Using coatings on the infrastructure is another potential method with nontoxic, biodegradable coatings being preferable. Although biodegradable coatings can be effective, they often do not last longer than a few months and are unsuitable longterm (Fitridge et al., 2012).

While there are many promising techniques used in controlling biofouling within aquaculture, they are not entirely effective and can be expensive with potential environmental impacts (Fitridge et al., 2012; Sievers et al., 2014; Lacoste \& GaertnerMazouni, 2015); consideration must also be given to the potential for bio-accumulation of any toxic coating components in the species being farmed. There will not be a one stop 
solution to fouling in aquaculture due to the multitude of different stock species farmed, operational methods and set-ups involved, however, this highlights the importance for a more holistic approach to understanding the ecology of biofouling within different environments.

\subsubsection{Coatings}

Probably the most notable marine antifouling technique is the use of biocide coatings on submerged surfaces. They can be highly effective as they kill biofouling organisms, however, because of their harshness and non-selectiveness they can be highly problematic to the environment (Rosenhahn et al., 2010). Due to its ecotoxicity and bioaccumulation, TBT reduces the effectiveness of immunological systems in fish, reducing reproduction abilities and causing imposex (masculinisation of female organs) in some invertebrates or bioaccumulating in marine mammals, and this has resulted in either restriction or a total ban on such harsh biocides (Iwata et al., 1997; Nehring, 2001; Almeida et al., 2007; Karlsson et al., 2010). The biocides on boats being stored on land can still cause issues within the marine environment, with antifouling paint particles (APP) being produced during maintenance and cleaning of boats or simply by paint peeling off abandoned or grounded vessels, and the APP are then either washed or blown into the marine environment. Due to their size, APP have a relatively greater surface area exposed to the marine environment compared to painted hulls and therefore, leach biocides and trace metals into the environment at a quicker rate. In environments with low turbidity, APP are more likely to settle and become a persistent source of biocides (Turner, 2010).

While TBT and its derivatives were banned, or heavily restricted, similar rules were not introduced for copper based products which were often used alongside the TBT based coatings to provide broad coverage. The use of copper based products has been questioned because the decision not to ban or restrict copper was because it is an element naturally found in the marine environment and is essential for growth in plants and animals (Voulvoulis et al., 1999; Yebra et al., 2004; Karlsson \& Eklund, 2010). Conflicting studies surround the effect of copper in antifouling coatings on the nearby environment (Voulvoulis et al., 1999; Piola \& Johnston, 2006; Karlsson \& Eklund, 2010). It has been argued that the estimated 3,000 tonnes of copper released annually into the marine environment are inconsequential compared to the estimated 250,000 tonnes released per year from natural 
sources (Yebra et al., 2004; Almeida et al., 2007). Others argue that to maintain the effectiveness of TBT free paints, the level of copper would have to be increased which could cause an increase of copper retained in surrounding marine organisms (Nehring, 2001). As there are many flora and fauna that are tolerant to copper, it would, therefore, be necessary to use another toxic chemical alongside copper to cover a wider range of fouling organisms, to fill the void of TBT based coatings (Almeida et al., 2007; Nehring, 2001). Other biocides have been developed, yet these products still have the potential to be just as harmful to the environment as TBT.

New types of coatings have been developed with a wide range toxicity. Organic booster biocide compounds used in conjunction with copper based coatings are a suitable option to help combat copper tolerant organisms (Nehring, 2001). The toxin release technique is often like TBT based coatings in which the toxin is combined with a polymer binder with the toxin being released slowly over time (Nehring, 2001). Although this change might reduce the issues associated with TBT based paints, they could potentially create new ones (Garcia et al., 2015). It could be considered that organic booster biocides are not a viable environmentally friendly substitute to TBT. Soluble matrix coatings have also been produced using binders on rosins (a type of resin) that have incorporated toxic compounds like copper or zinc. These coatings can only combine low levels of toxins, have a weak mechanical strength and require a thin coating. They are therefore easily eroded and are only effective for 12 -15 months and are not effective in the protection for slow moving or stationary vessels (Almeida et al., 2007). Another option is the use of insoluble matrix coatings which use high molecular mass binders like acrylic or vinyl that are insoluble in seawater, these coatings have stronger mechanical strength and can incorporate higher levels of toxins. However, over time the release rate of the toxins will decrease, and they become less efficient. Therefore they are only effective for $12-24$ months and are limited to particular types of vessels (Almeida et al., 2007).

Hybrid coatings are another example of TBT alternatives that have been used with some success, however there is much work involved in the development of these coatings, ensuring the compounds work well together while lowering their environmental impact, ensuring the correct formulation for the controlled release of biocide while maintaining the effectiveness of commercial products (Azemar et al., 2015). Using polymers extracted from 
natural rubber to create a base for antifouling coatings may be an eco-friendly alternative to many toxic coatings as natural rubber is a renewable resource. Also, because the biocides are covalently fixed to the polymer, the leeching of the biocides into the surrounding ecosystem is nearly undetectable. An ionic coating created using the polymer polyisoprene, which showed antifouling capabilities, has the potential to be an effective antifouling tool. The coating helped reduce fouling by hindering the growth of marine bacteria and fungi, reducing the adhesion of micro algae and hampering the attachment of spores (Jellali et al., 2013).

Silicone based coatings have been around since the 1980s and have benefits associated with the 'non-stick' concept of silicone based products. It reduces the effectiveness of the fouling organism's adhesion to the surface and maintains a low surface tension in the biocompatible range. The reduced adhesion also allows water currents to remove attached organisms simply; however, this can also cause the silicone compounds to be released into the water column as well. Developing a silicone based coating that is resistant to a wide range of fouling organisms will be difficult as there are still several obstacles that will need to be overcome such as improving their effectiveness once the surface has been biofouled. (Zhang et al., 2017). The research into the decomposition, ecotoxicity and bioaccumulation of silicone based coatings is limited and more work needs to be done on their environmental impact and should include the undercoats applied as they are corrosive and often contain high levels of carcinogenic polycyclic aromatic hydrocarbons (Nehring, 2001). Foul-release coatings are eco-friendly, cost effective and non-stick using functional technology over biocides; they are based on either silicone or fluoropolymer compounds and only require one coating compared to the two-three needed for biocide based coatings. The topography of the coatings surface reduces drag resistance, helps increase vessel speed while minimising fuel consumption; the coatings are considered long lasting (5-10 years) and because they do not rely on biocides and their non-stick nature they tend to require less maintenance and repair (Selim et al., 2017). In a hypothetical scenario of a total conversion to foul-release coatings, it is predicted that it could prevent the environment from receiving more than seventy billion tonnes of copper-based biocides, six million tonnes of organic biocides and twenty million litres of solvents per year (Yebra \& Catala, 2011). Foul-release paints reduced fuel consumption in tankers and bulk cargo 
vessels (Corbett et al., 2011). Switching to foul release coatings for all such vessels in the international fleet would reduce costs and lower emissions (Corbett et al., 2011). Even though foul-release coatings are cost effective and environmentally friendly, they do have some setbacks. Removing organisms that have successfully adhered to vessels requires them to be moving, the coatings tend to be soft and therefore can be damaged easily, and they are unsuitable for static objects because the coatings can leach compounds (Buskens et al., 2013).

Natural compounds could potentially be an alternative to organotin compound based paints, although identification and extraction of potential compounds with antifouling properties is still needed (Yebra et al., 2004; Qian et al., 2010). There is also the added issue of developing a natural compound into a commercial product once a compound has been identified, and there is also no assurance that the compound would have a lesser effect on the environment than current biocide booster based paints (Qian et al., 2010). While a system based on natural products may not be a complete solution to surface fouling, a complete comprehension of how they function is still vital. There is a strong need to carefully study and fully understand the behaviour and effects of pre-existing and new compounds and chemicals used in antifouling coatings ensure the most efficient and environmentally sound products are being used (Yebra et al., 2004).

More "eco-friendly", "Green" biocide-free paints have been developed and are marketed as a non-toxic, economical alternative (Garcia et al., 2015). However, they are often are more toxic to non-targeted organisms than the biocide based paints (Nehring, 2001; Karlsson \& Eklund, 2004; Karlsson et al., 2010). Hybrid paints are almost as efficient as the obsoleted TBT paints and are often a more suitable economic alternative (Azemar et al., 2015). Although these techniques still have disadvantages, the coatings on hulls can influence drag resistance. With all coating technologies, the age of the coating, how it was applied and static seawater conditions also impact the coatings drag capabilities (Lindholdt et al., 2015).

\subsubsection{Alternative Antifouling Techniques}

Several other initiatives include increased research focusing on the role of biofilm, the production of biological based paints and proactive preventative solutions such as 
rotating grooming brushes, the use of targeted vibrations for individual species and examining the surface topography of organisms with natural antifouling properties (Dobretsov \& Qian, 2006; Gribben et al., 2006; Hopkins \& Forrest, 2008; Vrouwenvelder et al., 2010; Choi et al., 2013; Maleb et al., 2013; Lindholdt et al., 2015; Tribou \& Swain, 2015). The research into non-toxic alternatives to biocides is steadily growing as we continue to gain a broader understanding of how these organisms behave in response to different stressors. There is now a focus on chemical free preventative solutions to fouling with low environmental impacts.

The first stage of biofouling is the formation of a biofilm, which can occur within a few minutes of being submerged and is often comprised of several different microorganisms (bacteria, diatoms, cyanobacteria, etc.). Biofilms can increase the drag of vessels, cause corrosion and can produce chemicals that affect the settlement of other fouling species, typically the second stage colonisers. Research into microorganisms that produce chemicals that inhibit the fouling of other organisms suggests that many of these species can act as natural anti-foulers however, there needs to be a greater understanding of the mechanisms and how they interact with other fouling organisms if they are to be commercialised (Qian et al., 2010; Dobretsov et al., 2013).

The chitosan-zinc oxide nanoparticle hybrid coating has demonstrated biofilm antifouling properties; chitosan is renewable, biodegradable and is a natural compound produced by the partial deacetylation of chitin (Al-Naamani et al., 2017). Chitosan has antialgal, antifungal and antimicrobial properties, however on its own, as an anti-fouler, it has low mechanical strength and is only usable short term. Hybridising it with zinc oxide increases the coatings mechanical strength, and zinc oxide has also displayed antimicrobial properties and low toxicity. The coating significantly reduced the growth of bacteria, diatoms and microorganisms, displaying its potential to be effective against biofilm fouling (Al-Naamani et al., 2017) Other natural sources of anti-fouling compounds are being investigated, with promising results. The compounds furanones and elatol were isolated from red algae and displayed strong anti-fouling properties (Fusetani, 2004). Marine invertebrates may also have anti-fouling compounds as many species have developed chemical defences. For example, isocyanide was isolated from sponges and nudibranchs and displayed anti-barnacle activity (Nogata \& Kitano, 2006; Qian et al., 2010). Several terrestrial 
plants also have anti-fouling compounds, for example, cycloviolacin 02, matrine, capsaicin, $\mathrm{N}$-vanillylnonamide, and anandamide (effective anti-fouling properties) (Qian et al., 2010). Compared to commercial vessels, US navy ships tend to spend longer in harbours, where the marine environment has high fouling pressures allowing fouling organisms to build up on the hulls over time. The vessels often require in-water hull cleaning; this method can damage surface coatings or increase the release of toxins. However, regular, underwater grooming with a mechanical rotating brush may be an effective preventative method of reducing biofouling, decreasing coating damage and dry-dock maintenance (Tribou \& Swain, 2010). Frequent use of a rotating brush system either two - three times a week, weekly, biweekly or monthly were effective in removing biofilms and reducing the settlement of macrofouling organisms, however, stubborn biofilms were more resistant and during periods of high fouling settlement, increased frequency of cleaning was more efficient at reducing fouling (Tribou \& Swain, 2015; Hearin et al., 2015; Hearin et al., 2016; Tribou \& Swain, 2017). The hull coating regardless if it was an ablative copper, antifouling coating or a silicone based fouling release coating appeared to sustain minimal damage from the grooming process, suggesting that it could reduce overall costs associated with increased fuel consumption (due to increase drag), reducing the frequency of dry dock maintenance and potentially increasing the life of the coating (Tribou \& Swain, 2015; Hearin et al., 2015; Hearin et al., 2016; Tribou \& Swain, 2017).

\subsection{Sound}

\subsubsection{Natural Underwater Sound}

Natural underwater sound is formed from numerous abiotic, biotic and anthropogenic sources, with different marine ecosystems having their own soundscapes. In recent years, we are discovering that it plays a far greater role in marine ecology than previously thought (Butler et al., 2016; Menze et al., 2017). However, there are still limitations in the research and understanding of the role of sound within the marine environment (Hawkins et al., 2015). Several different marine habitats have distinct underwater soundscapes that could be used as settlement cues for a wide range of marine organisms and this has led to an increase in studies into the effect of noise on the movement and settlement choice of larvae (Jung \& Swearer, 2011; Wilkens et al., 2012; Lillis et al., 2013). 
Soundscapes in the Arctic fluctuate seasonally, with an increase during summer due to a surge in iceberg cracking and break up events caused by temperature change and wind. Ambient underwater sounds were recorded at Kongsfjorden, Arctic over a summer period. The sound of iceberg calving was between $100 \mathrm{~Hz}-500 \mathrm{~Hz}$ and the sound of icebergs bobbing was between $200 \mathrm{~Hz}-400 \mathrm{~Hz}$ (Ashokan et al., 2016). Icebergs produce two types of sound: harmonic tremors and broadband bursts. Harmonic tremors are associated with aground and adrift icebergs in the Antarctic region and produce a low frequency $(1 \mathrm{~Hz}-$ $10 \mathrm{~Hz}$ ) that can last up to four hours and may be recorded 1000s of $\mathrm{km}$ away from the source (MacAyeal et al., 2008; Matsumoto et al., 2014). Broadband bursts are linked to the breakup of icebergs in the ocean most likely cause by disintegration and edge wasting (Matsumoto et al., 2014). Iceberg breakups within the Southern Hemisphere create an important natural sound source within the Antarctic marine ecosystem as it is considered a leading sound source, and has the potential to alter ambient underwater soundscapes throughout the ocean (Matsumoto et al., 2014). In 2007 after two enormous icebergs broke away and drifted into the Southernmost Pacific Ocean; high-intensity sounds from this break up were recorded in the mid-equatorial latitudes, affecting the soundscapes in those areas for nearly two years. This indicates that the Antarctic iceberg cycle can potentially affect both local marine ecosystems and the soundscapes of environments further away than previously thought (Matsumoto et al., 2014).

The larvae of different species of reef fish employ different habitat selection methods directly using sound; the two main strategies were: using sound directly to select a suitable habitat and avoiding habitats due to sound (Parmentier et al., 2015). Marine and brackish Sand Goby species will manipulate sand within their nests to influence the sounds they emit during mate selection. The males build nests and will emit a sound when a female enters their nest; females prefer larger males with large, well-built nests. The size of the male will affect their sound and nests that are larger and better constructed will also amplify the males sound. Females appear to listen to the sound amplitude to evaluate a potential mate, suggesting that sound plays a crucial role in mate selection and fitness (Lugli, 2013). The larvae of some coastal marine organisms can be affected by natural underwater sound, showing a directional movement towards certain sounds (Radford et al., 2007). Attaining a comprehensive understanding of how fouling organisms respond to a diverse range of 
stressors is vital in producing effective solutions that meet these requirements.

Furthermore, the noise generated by vessels within a harbour is often in the frequency range $100-1000 \mathrm{~Hz}$, which is biologically significant for larval settlement of some marine organisms (Montgomery et al. 2006; Gotz et al. 2009).

\subsubsection{Anthropogenic Underwater Sound}

Human related activities in and around the ocean, such as commercial shipping, oil and gas expeditions, fishing practices, sonar, scientific surveys, dredging and other maritime activities have contributed to marine sound pollution (Hawkins \& Popper, 2017). The levels of low-frequency of underwater sounds have been slowly increasing in global oceans for several decades (Wenz, 1969; Ross, 1976; Andrew et al., 2002; Andrew et al., 2011; Chapman \& Price, 2011; Širović et al., 2016; Kaplan \& Solomon, 2016). This has been attributed mainly to commercial shipping which is linked to global economic trends. Models using economic growth and projected shipping activity have been used to predict future ambient underwater sound levels, with current estimates showing an increase (Frisk, 2012; Kaplan \& Solomon, 2016). Adverse effects of anthropogenic sounds have long been established in marine mammals and other marine organisms with studies indicating abnormal growth and reproduction of finfish species and certain shellfish caused by highlevels of human-induced noise (Myrberg, 1990). Exposure to artificial sound can cause stress in several different fish species, where it may affect their swimming, territorial behaviour, predator awareness and their efficacy to find food. The European Seabass responded to sound exposure by increasing their speed and depth at which they swam as well as showing directional movement away from the source of the sound indicating that anthropogenic sounds can affect the behaviour of some marine organisms (Neo et al., 2016).

Within the last decade there has been increased research into how the larvae of marine organisms behave, through locomotion; sensitivity to light; chemical cues and their response to noise (Burgess et al., 2009; Clay \& Grünbaum 2010; Jung \& Swearer, 2011; Lillis et al., 2013; Sams et al., 2015). The settlement of reef fish and invertebrates in response to the noise produced by wave action on a reef and the active habitat selection due to distinct habitat sounds as well as the directional response to sound cues have been examined (Radford et al., 2007; Jung \& Swearer, 2011; Lillis et al., 2013; Eggleston, 2016). Results suggest that many species can respond to sound in different situations. However, since 
many marine organisms respond to natural soundscapes, there is increased concern that human-induced sound may be affecting these species. For example, the larvae of reef fish did not significantly react to the presence of boat sound, but when exposed to pier and boat sound together significantly more larvae were trapped compared to a control (Jung and Swearer, 2011). This suggests that noise within harbours may be affecting the behaviour of biofouling larvae by increasing their settlement rate in the harbour and possibly increasing their development and survival rates. This implies that the sound produced inside harbours could essentially increase biofouling on vessels and thus the risk of spread of invasive species, putting more economic pressure on companies.

The larvae of the biofouling mussels Perna canaliculus settled significantly faster in the presence of noise than the control (Wilkens et al., 2012). Similarly, the settlement, metamorphosis and survival rate of Ciona intestinalis (a biofouling ascidian) larvae increased when exposed to the sound of a vessel generator (McDonald et al., 2014). This suggests that human-induced sound from vessels may be encouraging the development and survival of biofouling species (Wilkens et al., 2012; McDonald et al., 2014). Further research needs to be conducted to gain a better understanding of the vital role of sound in stimulating biofouling larvae and the influence it has in marine ecosystems (Stanley et al., 2014).

\subsection{Bryozoa}

Phylum Bryozoa (Greek for 'moss animal') is a relatively large phylum of mostly marine, colonial invertebrates, with approximately 6,000 known living species and 15,000 identified in the fossil record. They tend to be either encrusting or grow as tufts with varying shape and size that means they are often misidentified as corals and hydroids. They have often been referred to as lace corals, moss animals and sea mats (Gordon, 2003; Gordon et al., 2009). Bryozoan colonies are made up of individual zooids that often have a calcium carbonate skeleton; the skeletons are used as the most common way to identify bryozoans down to the species level. Most species display hermaphroditic tendencies with testes and ovaries developing at different times in an individual zooid, while other species display specialised male and female zooids within a colony (Gordon, 2010).

Bryozoa commonly can act as fouling organisms due to their sessile nature and encrusting abilities (Gordon \& Matwatari, 1992). With the increase in shipping vessels and 
trade pathways in the last century, several bryozoan species have extended their distribution worldwide using via vessel fouling.

\subsubsection{Biofouling Bryozoa}

There are several bryozoa families that are common biofoulers, and the Phylum is listed in numerous catalogues and reviews as a top fouler. Many species have managed to spread globally causing several issues for many marine industries (Gordon \& Matwatari, 1992). Fouling bryozoa can cause both direct and indirect damage to many of the substrates they foul, with some species being more effective space competitors in aquaculture setups than the cultured stock creating an economic and stock loss in this industry.

The Watersiporidae is a well-established biofouling family, and many of its species spread worldwide, mostly via vessels as vectors. In the 1950s, this family was considered a problematic fouler as it was often resilient to moderately toxic paints on hulls, acting as a substrate for other biofoulers to settle on and thus avoid the toxic paint (Wisely, 1958). The invasive bryozoan species Watersipora subatra has resilient and persistent effects on community structure, where it influences the abundance of several different taxa (Sams \& Keough, 2012). Bryozoa larvae tend to be non-feeding, as this stage is a relatively short stage in their life cycle; and this implies that they are often not fastidious when selecting a substrate to settle on making them very suitable for biofouling (Zimmer \& Woolacott, 1989 A).

\subsubsection{Bryozoa Larval Behaviour}

It has been previously thought that most larvae have very little control over where they drifted and eventually settled; however, there is now a growing body of evidence that suggests this is not the case. Most bryozoan larvae have eyespots and can sense light and show some form of phototaxis; they are often equipped with cilia that may serve several purposes such as locomotion, feeding and 'crawling' across a substrate until a suitable location is found.

The larval behaviour of bryozoan species has been considered in many behavioural studies to help elucidate their interaction with the surrounding environment (Marshall \& Keough, 2003; Santagata, 2008A; Burgess et al., 2009). The size and age of a larva can significantly affect how much time it spends in the water column, the selectiveness of a 
suitable substrate, and can even affect the community assemblage post-settlement (Marshall \& Keough, 2003; Burgess et al., 2009; Davis \& Marshall, 2014).

The delayed settlement of the bryozoan Bugula flabellate larvae caused by increased waterflow that prevented settlement over multiple generations had lethal and sub-lethal effects on the colonies suggesting that low water movement was a favourable condition for larval release (Cancino \& Gallardo, 2004). Some Watersipora subtorquata larvae survived long term exposure to copper although they were slow growing, and the overall survivorship was affected (Ng \& Keough, 2003). These studies highlighted that the conditions the larvae are exposed to could have long lived side effects through multiple generations (Ng \& Keough, 2003; Cancino \& Gallardo, 2004). Multiple studies have been conducted on the response of bryozoan species to light as most species will release larvae under light shock treatments. Several bryozoa species display positive phototaxis within the first few hours of release; they will then display negative phototaxis presumably so that they will settle on the benthos (Wendt \& Woolacott, 1999; Cancino \& Gallardo, 2000; Santagata \& Zimmer, 2000).

The effects of sound have not yet been fully explored within the Bryozoa, however previous studies on the effect sound has on biofouling larvae has suggested that bryozoa could display a response to the presence of noise, either natural or human-induced; this remains an area largely under research. The larvae of some bryozoan species have demonstrated a potential response to sound during settlement suggesting the possibility of sensory organs capable of responding to sound within the bryozoa phylum (Stanley et al., 2014).

\subsection{Proposed Aims and Hypotheses}

Biofouling is a global issue that not only negatively affects local ecosystems with the invasion of non-indigenous species into long established environments but also increases the fuel consumption of vessels, reduces the profitability of aquaculture industries. Billions of dollars are spent annually on the prevention, treatment and removal of fouling material and research. As alternative methods are developed to reduce fouling issues, there has been an increase in novel solutions to this problem. The effect of noise on bryozoan species 
remains largely unexplored even though the phylum is one of the biggest contributors to biofouling.

I aim to gain a better understanding of the role vessel noise plays in biofouling bryozoan larval behaviour, as a novel way to approach a possible eco-friendly solution to biofouling. For my thesis, I will examine the morphology of W. subatra larvae using scanning electron microscopy (SEM) to determine potential sound sensory organs. I will also explore the effects of noise on the larval behaviour of a common, fouling bryozoan species: Watersipora subatra (Ortmann, 1890) in the Wellington region to gain a better understanding of the role of sound in biofouling. My first hypothesis is that if bryozoan larvae can respond to sound, then they must have organs capable of sensing sound, my second hypothesis is that the larvae of bryozoan species will respond to the presence of noise by increasing their settlement rate. If this holds true, my third hypothesis is that the bryozoan larvae will respond differently to certain frequencies and to ascertain which frequencies promote or deter the settlement of the larvae.

For this thesis, I have written Chapter 2 and 3 in the style of scientific papers, because of this there will be some repetition within my chapters. 


\section{Chapter Two: Scanning electron microscopy of Watersipora subatra larval morphology}

\subsection{Introduction}

Adaptations during the larval stage of many marine species are imperative to the individual's survival and development as well as the overall fitness of the species. Larval morphology is significant in understanding the life histories of a marine species and their ecology, as many factors that influence the larval stage of a species can have latent effects in other life stages (Cancino \& Gallardo, 2004; Pechenik, 2006). Marine organisms employ different larval strategies: some are planktotrophic with a significantly long pelagic duration in the water column and are capable of feeding to acquire the nutrition to sustain this stage and to aid settlement. Others are lecithotrophic and are either nonplanktonic or will spend a relatively short period (hours to a few days) in the water column; lecithotrophic larvae have a yolk sac that supplies nourishment for this stage and settlement, and they are therefore usually nonfeeding (Jablonski \& Lutz, 1983). Interestingly some planktotrophic larvae have short pelagic periods and while they do feed, it is not required for their settlement and metamorphosis; also, some lecithotrophic larvae are capable of feeding (Allen \& Pernet, 2007). This implies that larval strategies are not straightforward and that there are numerous advantages and disadvantages to different strategies and adaptations (McEdward, 2000; Allen \& Pernet, 2007). The longer pelagic stage of the planktotrophic larvae allows for a greater dispersal range; however, this increases the mortality by raising the larvae's exposure to predators in the water column and reducing the likelihood of encountering a suitable habitat (Jablonski \& Lutz, 1983; Pawlik, 1992). Because lecithotrophic larvae are usually nonfeeding they can only survive for shorter periods in the water column; this reduces their dispersal range and decreases the chance of finding a suitable habitat, although an advantage of the shorter time in the water column means there is a reduced risk of encountering pelagic predators (Jablonski \& Lutz, 1983). The reproductive effort for lecithotrophic larvae is greater compared to planktotrophic larvae; they also tend to have a reduced mortality compared to their pelagic counterparts. 
However, the fecundity of the parents of lecithotrophic larvae is significantly less than the parents of the planktotrophic larvae (Jablonski \& Lutz, 1983; McEdward, 1997).

While there is typically a dichotomy in classifying larvae as either feeding or nonfeeding, it is evident that the larvae of marine organisms employ several different morphological and behavioural characteristics, not only for nutritional gain but also for defence, locomotion, dispersal, habitat selection and predatorial habits. Therefore it is important to comprehend these features to gain a greater understanding of their ecology and life histories. Larval movement in the water column and the required morphological features are poorly understood due to their size and the difficulty in studying their movements in situ, which can cause limitations in understanding their dispersal and ecology (Clay \& Grübaum, 2010). While it is debatable that larvae have insufficient ability to control their movements, and will drift in the water column, many species can move vertically in the water column. This depth adjustment allows them to take advantage of currents for dispersal, to avoid predators and to locate a suitable habitat (Garrison, 1999). The different developmental stages of larval sand dollars allow the larvae to move vertically to depths that are advantageous for that larval stage, using different morphological traits in each stage (4-, 6-, and 8-armed stages); this vertical preference perhaps allows the larvae to avoid intra-specific competition, and these morphological adaptions can influence larval development (Clay \& Grübaum, 2010). Sand dollar larvae also use chemical cues from adults to select a suitable habitat, as a common predator is often unable to establish its self within a pre-existing sand-dollar bed, thus reducing the mortality rate. In addition developing the ability to detect species-specific chemicals has allowed sand dollar larvae to increase their survivability post-settlement (Highsmith, 1982). The morphology and behaviour of some coral reef fish larvae have enabled them to have some control over their movements in the water column, enabling the larvae to have an active role in self-recruitment and avoid the ocean's currents. Therefore understanding the adaptions for locomotion will help elucidate how much control a larva can have over its dispersal and the subsequent effects on recruitment and population dynamics (Fisher \& Bellwood, 2003)

One of the biggest challenges that face marine larvae is mortality; specific adaptations can significantly improve an individual's chance of survival to adulthood. This is especially true with so many factors influencing the mortality rate like larva size, predator 
encounters, defence strategies, delayed settlement, environmental factors, inability to locate a suitable habitat, and resource gathering (Marshall \& Keough, 2003; Cancino \& Gallardo, 2004; Davis \& Marshall, 2014). The population dynamics of the North Sea Herring are affected by larval mortality, with the recruitment rate and stock population appearing to correlate with larval mortality. There is a possibility that larval mortality could be used to help predict future stock populations within the Herring fisheries industry (Fässler et al., 2011). Interestingly, more robust models can be used to predict population dynamics, and could be utilised to estimate recruitment and mortality (White et al., 2014). It is commonly thought that larval mortality rates are high. However, these more complex models can sometimes challenge this assumption previously made about the larval mortality rate of some invertebrates, which appears to be significantly lower than previous estimates (Metaxas \& Saunders, 2009; White et al., 2014). The larvae of two intertidal mussel species can detect Dogwhelk predators and employ different survival methods depending on the surrounding habitat (von der Meden et al., 2015). Both species exhibited a preference for the presence of Dogwhelks, in one site, employing a predator satiation method, where they settled in higher densities, reducing the individual's probability of being a prey; while at the other site, both species typically demonstrated predator avoidance. This indicates that some larvae can adjust their behaviour depending on the immediate environment and presence of predators to reduce their current mortality rate, suggesting that they have sensory characteristics that can assess the surrounding environment (von der Meden et al., 2015). Improved knowledge of the morphology of larvae can help understand how species reduce their mortality rate and post-settlement success.

Larval morphology is important in understanding life histories and ecology because events and factors that affect an individual larva can affect its later stages either positively (e.g. increased food availability can improve post-settlement development and survival rate) or negatively (e.g. poor habitat selection can increase starvation, reduce reproductive success) (Pechenik, 2006; Hamilton et al., 2008). Settlement delay is an interesting concept in larval development especially in lecithotrophic larvae as they are limited by the size of their yolk sac. As time goes on and their food source diminishes, there is a greater pressure to find a suitable settlement location before either starvation or simply running out of enough resources to undergo metamorphosis (Cancino \& Gallardo, 2004; Sams et al., 2015). 
The tentacle crown (previously known as a lophophore) is the feeding appendage of adult bryozoans, and a delay in settlement of a larva will decrease the size of the tentacle crown in Bugula neritina, reducing an individual's feeding capabilities. This relationship can be used in reverse to estimate the settlement delay of larvae (Burgess \& Marshall, 2011). Certain other larval traits can also carry over into other life stages and influence behaviour. The body length of common coral reef fish larvae at settlement affected the larva's choice to remain solitary (higher mortality) or join a group (reduced mortality) post-settlement, with longer (typically better condition) larvae more likely to participate in a group (Dingeldein \& White, 2016). Surprisingly larvae in better condition post-settlement also increased their foraging which in the immediate future increases the mortality risk, however, the increased foraging does allow for faster growth which over time will lower the risk, suggesting that larval traits can influence the survival rate of other life stages (Dingeldein \& White, 2016)

The Bryozoa phylum contains mostly marine, colonial invertebrates, commonly with a free-swimming larval stage, this phylum is of interest as it is relatively understudied despite their ecological importance in some benthic communities, and despite the fact that many species are prolific biofoulers. Increasing our knowledge of their life cycles and ecology is important in understanding their relationship to their environment and developing effective ways to reduce their fouling capabilities and reduce their invasive tendencies (Gordon \& Matwatari, 1992; Gordon et al., 2009). Membraniporopsis tubigera is a bryozoan species that was previously unreported in New Zealand, but in 2001-02 became a nuisance in an Auckland harbour clogging flounder set nets, temporarily affecting the livelihoods of set net fishers; similarly, in Southern Brazil at the same time, the number of M. tubigera increased and clogged shrimp nets. Due to the limited knowledge of reproduction in M. tubigera, determining how this species reached Brazil and New Zealand is problematic; simply ascertaining whether the larvae were lecithotrophic or planktotrophic would help reduce the number of potential man-made dispersal methods (Gordon et al., 2006).

Bryozoans have a diverse range of larval morphological characteristics to help increase their survivability; most structures are attributed to aiding locomotion, phototaxis behaviour, suitable habitat exploration and metamorphosis. Beyond this, there is little known about their characteristics and whether they can are used in other types of 
behaviours (Santagata \& Zimmer, 2000; Santagata, 2008B). The age and size of bryozoan larvae also affect larval behaviour, potentially influencing whether an individual will look for a suitable habitat near its parent colony or risk entering the water column to drift further away in the hopes of locating a more beneficial habitat affecting dispersal patterns (Burgess et al., 2009). These endogenous characteristics coupled with external influences affecting larval behaviour suggests that bryozoan larvae can respond to a wide range of internal and external factors and adjust their reproductive strategies accordingly to increase their survival rate pre- and post-settlement (Seed \& Hughes, 1992). Therefore, increasing our knowledge of larval morphological characteristics and how they affect larval behaviour is important in understanding dispersal, recruitment patterns and overall population dynamics.

Phototaxis behaviour is typical of the invertebrate larvae of sessile organisms and is common among bryozoan larvae, which often display movement towards a light source shortly after release to aid in dispersal. Later they often move away from a light source when they are ready to begin looking for a suitable settlement location (Reed, 1991; Seeds \& Hughes, 1992). Marine zooplankton with phototaxic tendencies use eyespots to detect light and directly regulate their cilia movement. Therefore there tends to be a coupling between sensory and locomotive organs, and in some sponge and cnidarian larvae, they are combined into a single cell (Jékely et al., 2008).

Within the Bryozoan phylum, the family Watersiporidae, is well known for its biofouling tendencies, with global distributions for several species using vessels as vectors (Gordon \& Matwatari, 1992). Species within the family are often resistant to toxic antifouling paints, which can be challenging as they can then act as barrier between the paint and other fouling organisms (Wisely, 1958). The encrusting bryozoan Watersipora subatra is a common biofouler found in New Zealand with unknown origins (Vieira et al., 2014). The larvae of $W$. subatra. are typical of the phylum, they are non-feeding, free swimming with a short pelagic period and are relatively understudied. Previous observations have demonstrated that the settling period is generally consistent all year round with an increase in late spring to early autumn within the New Zealand population. The larvae of other species in the Watersipora family have demonstrated the potential to respond to sound which suggests that bryozoan larvae may have sensory organs that are able to 
respond to sound (Stanley et al., 2014). This chapter will examine the larval morphology and behaviour of $W$. subatra using visual observations and scanning electron microscopy to gain a better understanding of the sensory and locomotive organs that help influence behaviour and movement. 


\subsection{Methods}

\subsubsection{Adult collection and larval release:}

Mature, reproductive colonies of $W$. subatra were collected from Chaffers Marina, Wellington ( $\left.41^{\circ} 17^{\prime} 18.9^{\prime \prime} \mathrm{S} 174^{\circ} 47^{\prime} 06.1^{\prime \prime} \mathrm{E}\right)$ and were stored in a blacked-out tank overnight. The tank was kept dark by wrapping it in black plastic and ensuring that the main lights in the lab were off. An air pump was used to provide adequate aeration and water flow and the tank was filled with unfiltered seawater to provide a natural food source. After 15 hours, the adults were then exposed to an artificial light source $(150 \mathrm{~W}-200 \mathrm{~W})$ to induce larval release.

Light shocking was used to trigger spawning in sexually mature bryozoans in the lab. Adult colonies were kept in the dark for a set time (a few hours to 24 hours) before exposing them to a light source (natural or artificial); encouraging the adults to release their larvae (Reed et al., 1988; Wendt \& Woollacott, 1999; Cancino \& Gallardo, 2000; Santagata \& Zimmer, 2000).

The larvae were then collected using a transfer pipette and kept in a petri dish with filtered sea water, where they were observed under a microscope before SEM preparation. The swimming patterns, settlement times and their visual appearance were noted.

\subsubsection{Scanning Electron Microscope Preparation:}

Bryozoan larvae were fixed at room temperature by pipetting the specimens into a small glass vial. As much of the seawater as possible was removed, then $2 \mathrm{ml}$ of filtered seawater was added followed by $2 \mathrm{ml}$ of $4 \%$ osmium tetroxide. The larvae were kept in the vial in the solution for an hour under the fume hood before the solution was removed. The larvae were rinsed in distilled water several times, gently agitating the vial and removing the liquid before transferring the larvae to a clean glass vial and repeating the wash cycle twice more to ensure all traces of osmium tetroxide were removed.

The fixed larvae then underwent a gradual dehydration with ethanol up to a concentration of $70 \%$ ethanol and stored for up to two months. The dehydration was done by slowly introducing ethanol into the larvae solution starting at $10 \%$ concentration for 10 minutes before getting stronger every $10-15$ mins; the steps were: $10,20,30,40,50,60$, 
$70 \%$. Settled larvae were also fixed by this same process although prior to fixation they were settled onto a piece of acetate sheet that was then cut up into small pieces.

The specimens were put into a $90 \%$ ethanol solution for 15 minutes, minimising the amount of liquid from the storage container as well as covering the petri dish to avoid evaporation. The samples were then transferred to a $100 \%$ ethanol solution, avoiding as much excess liquid from the $90 \%$ solution as possible. The samples were then left covered in the $100 \%$ solution for 20 mins. This step was then repeated to ensure the highest ethanol concentration for the samples. Another small petri dish was filled with $100 \%$ ethanol, and a small porous container was placed in the middle and was allowed to absorb the ethanol. The samples were then pipetted into the porous container and to allow adequate mixing of the two solutions during the critical point drying (CPD) process without losing the samples.

Critical point drying is a process where gas pressure is raised to a point where there is no obvious difference between liquid or gas state of a medium; the surface tension is reduced to zero at a precise temperature and pressure, i.e. at the critical point. Drying biological samples this way avoids damage from surface tension. The critical point of water is $+374^{\circ} \mathrm{C}$ and $22145.96 \mathrm{kPa}$ which would cause heat damage to biological specimens. The EMS 850 (Electron Microscopy Sciences, USA), is a CPD that uses $\mathrm{CO}_{2}$ as the transitional medium, as the critical point of $\mathrm{CO}_{2}$ is $31^{\circ} \mathrm{C}$ and $7391.18 \mathrm{kPa}$. Typically the dehydration fluid (ethanol) which is miscible with $\mathrm{CO}_{2}$ will act as an intermediate fluid.

The CPD was performed according to the method of Cohen (1979). A wire mesh was used for transporting small specimens, and for larger specimens, a small porous pot was used. The specimens were maintained in the dehydration fluid immediately prior to CPD, then transferred to the EMS850 chamber. The chamber was pre-cooled to accommodate the liquid $\mathrm{CO}_{2}$, filled with ethanol, and the porous pots added to the chamber. The chamber was sealed and pressurised, then filled with liquid $\mathrm{CO}_{2}$ and the $\mathrm{CO}_{2}$ was vented through a needle valve. This was repeated until the solvent exchange was completed. The removal of all ethanol was checked by removing the plastic pipe from the exhaust outlet and placing a small piece of filter paper into the stream of gas, and if there was a small damp patch, then the solvent was still present and further cycles were performed. The chamber was then filled with $\mathrm{CO}_{2}$ a final time for $\mathrm{CPD}$, the chamber was then heated until the critical point at $35^{\circ} \mathrm{C}$ and $7391.18 \mathrm{kPa}$ was reached. This process normally took $\sim 1 \frac{1}{2} \mathrm{hrs}$. 
The chamber was then depressurised at 100psi/min over a 13-minute period, and the specimens were removed to be mounted on stubs prior to sputter coating and examination in the SEM. The larvae were mounted using a small metal pointer with a tiny hook at the end. Tools were grounded before using them to avoid possible static charge. They were then coated with gold palladium in the Quorum sc7620 (UK) sputter coater for 30 seconds and then placed in the SEM.

\subsubsection{Scanning Electron Microscopy}

SEM images were taken on either a JEOL, JSM-6610LA (Japan) or a Hitachi TM3000 (Japan). Images were then examined and compared to other images of the larvae of other bryozoan species to identify potential morphological traits and organs. 


\subsection{Results: Larval behaviour and morphology}

The coronate larvae of $W$. subatra were released from individual zooids within an adult colony after being exposed to a light source. The larvae displayed positive phototaxy shortly after being released from the adult colony and spent a majority of their freeswimming stage in the water column. The larvae are spherical in shape and crimson red with a corona that fluoresces blue in visible light under a light microscope (Figure 2.1A-B). The apical disc and the aboral pole of the larva are visible in Figure 2.1C as well as the oral ciliated epithelium and the oral undifferentiated cells. The apical disc has alternating bands of ciliated and unciliated cells radiating out from the apical disc. The larva is a dumbbell shape with three distinct regions: the aboral and oral hemispheres and the corona and are covered in cilia (Figure 2.1D). Note that in following images, the larvae are displayed in various orientations with one or the other hemispheres upper most. Figure 2.1D indicates the opening to the internal sac. Prior to settlement, larval behaviour changes as they become negatively phototaxic and begin to crawl along a substrate searching for an appropriate settlement location.
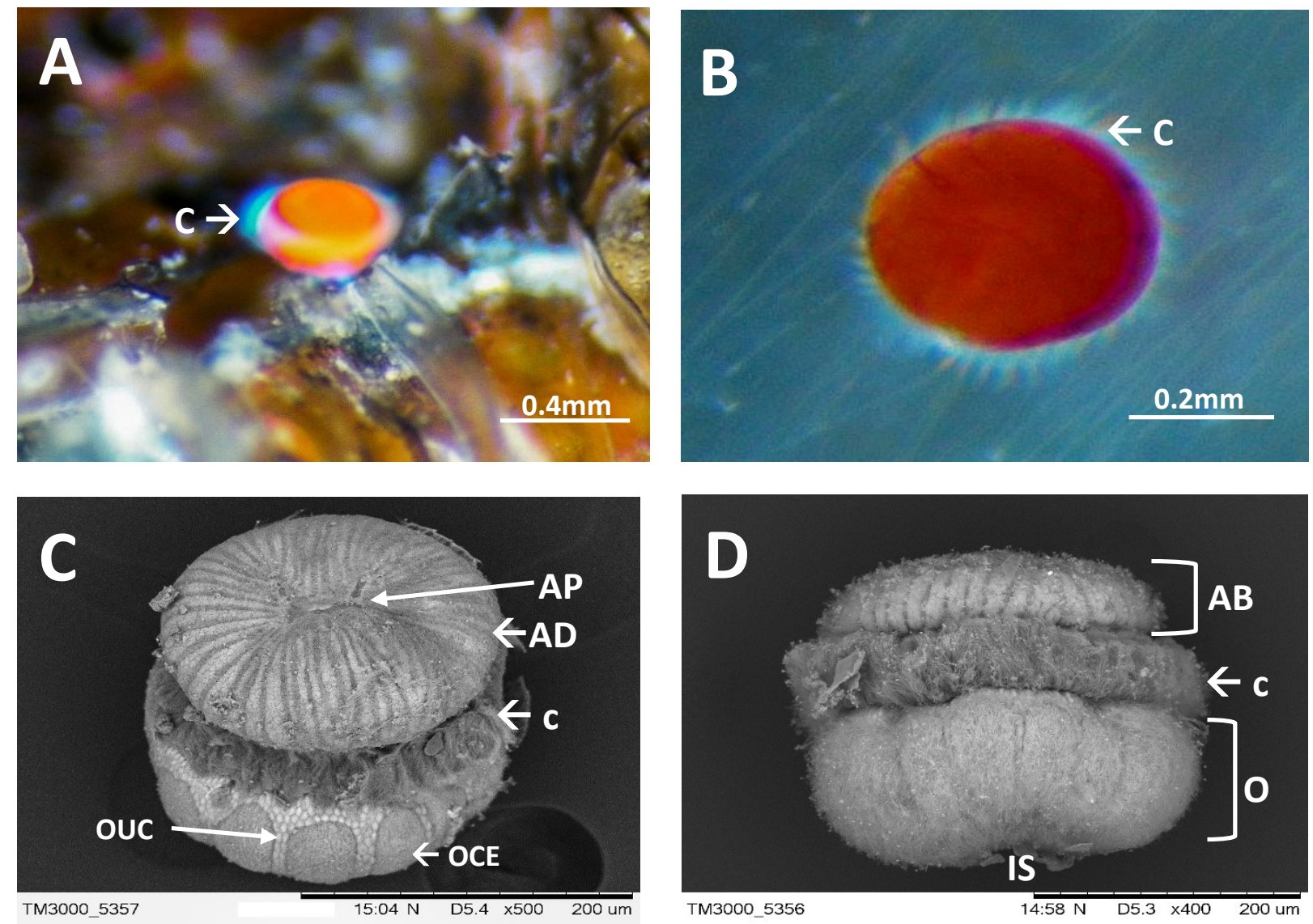

Figure 2.1 Watersipora subatra larvae. A-B: free-swimming larvae within an hour of release from the colony; C-D: SEM images of free-swimming larvae. c: corona; $\mathbf{A B}$ : aboral hemisphere; $\boldsymbol{O}$ : oral hemisphere; IS: opening to the internal sac; AP: aboral pole; AD: apical disc; OUC: oral undifferentiated cells; OCE: oral cilliated epithelium. 
The cilia of the corona (Figure 2.2A-B) create a band around the equator of the larva and are orientated in one direction. The larvae swim in a spiral pattern moving their ciliated corona in unison to create movement.
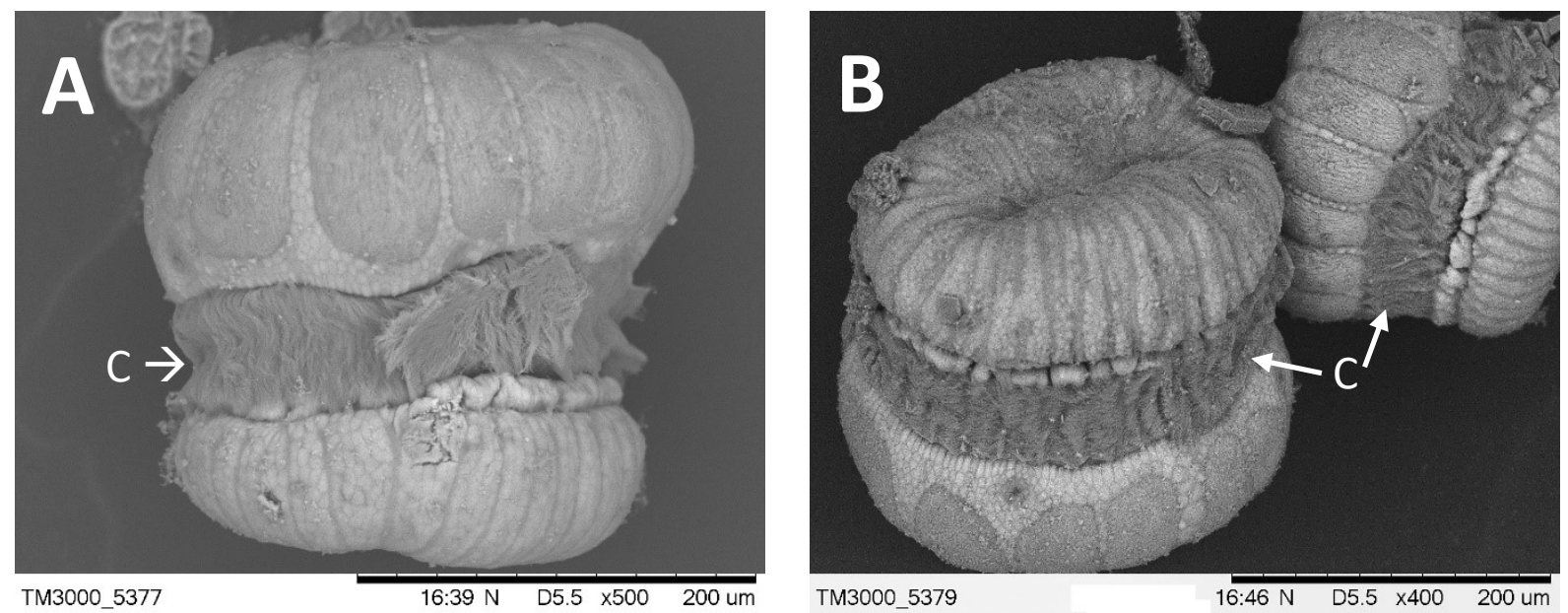

Figure 2.2 SEM images of Watersipora subatra larvae. c: ciliated coronal band
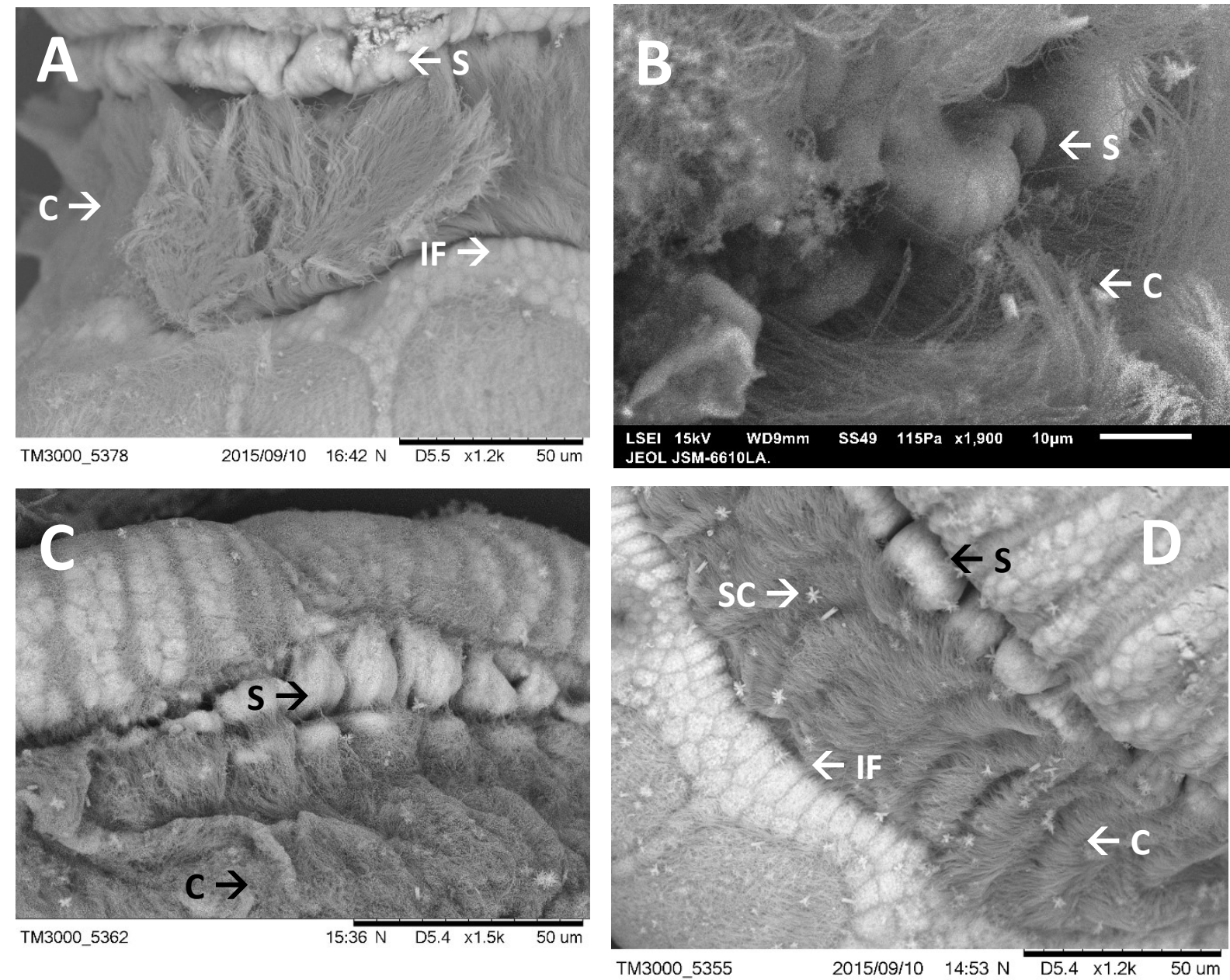

Figure 2.3 SEM images of Watersipora subatra larvae. S: supracoronal cells; IF: infracoronal cells; c: corona; sc: salt crystals. 
The supracoronal ring of cells (Figure 2.3A-D) attach the corona to the aboral hemisphere and run adjacent to the ciliated corona. The corona is attached to the oral hemisphere by infracoronal cells (Figure 2.3A \& D). Typical of bryozoan larvae that display phototaxic behaviour, W. subatra larvae have eyespots (Figure 2.4A-D). Eyespots are located in the infracoronal band of cells, they are $\sim 15 \mu \mathrm{m}-20 \mu \mathrm{m}$ across and appear pigmented and concave (Figure 2.4C-D). The eyespot in figure 2.4D is heavily covered with salt crystals.

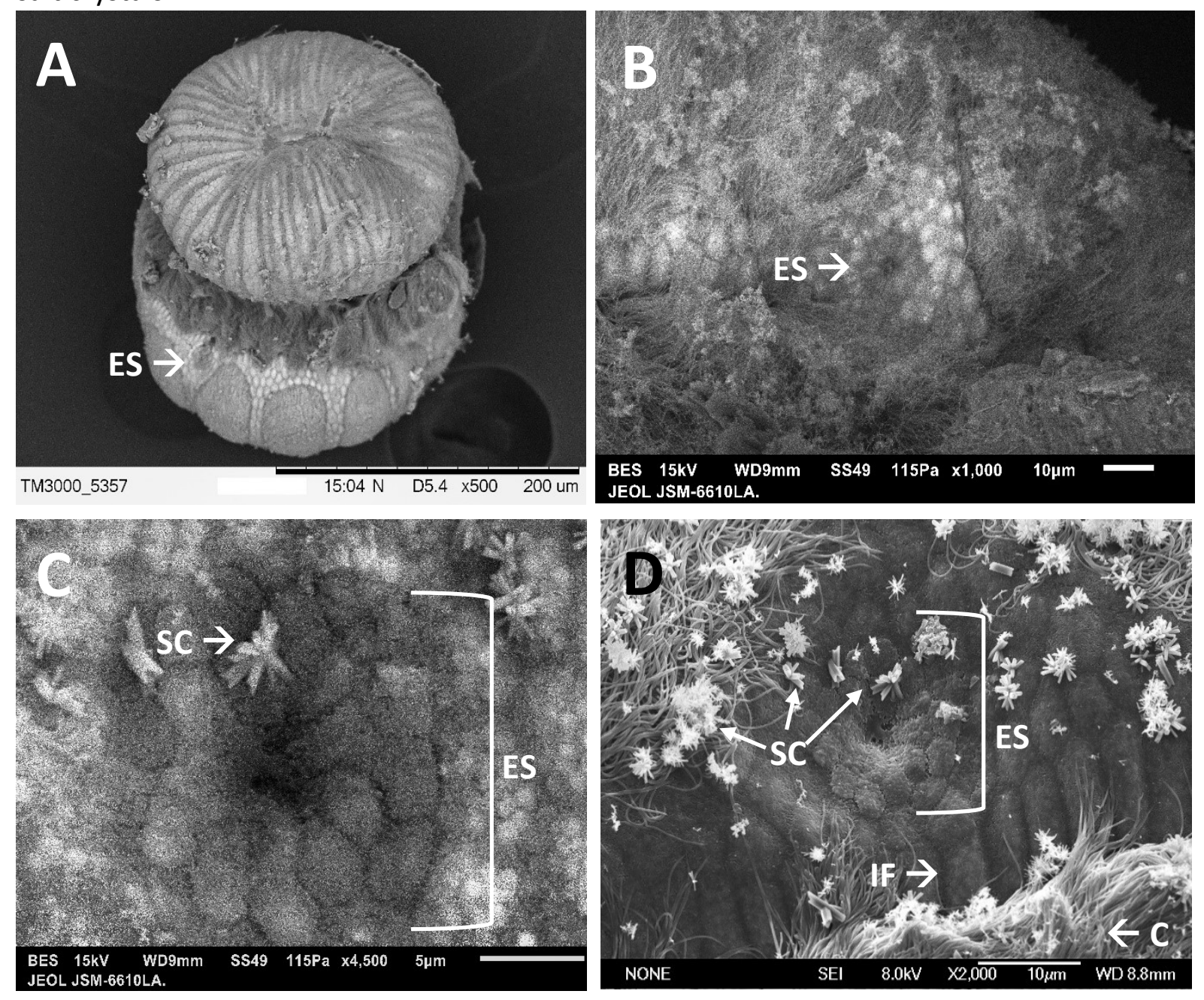

Figure 2.4 SEM images of Watersipora subatra larvae. ES: eyespot; IF: infracoronal cells; c: corona; sc: salt crystals 
Flagellar tufts, also known as balancers (Figure 2.5) are a group of elongated cilia located near the corona that protrude from the infracoronal band.

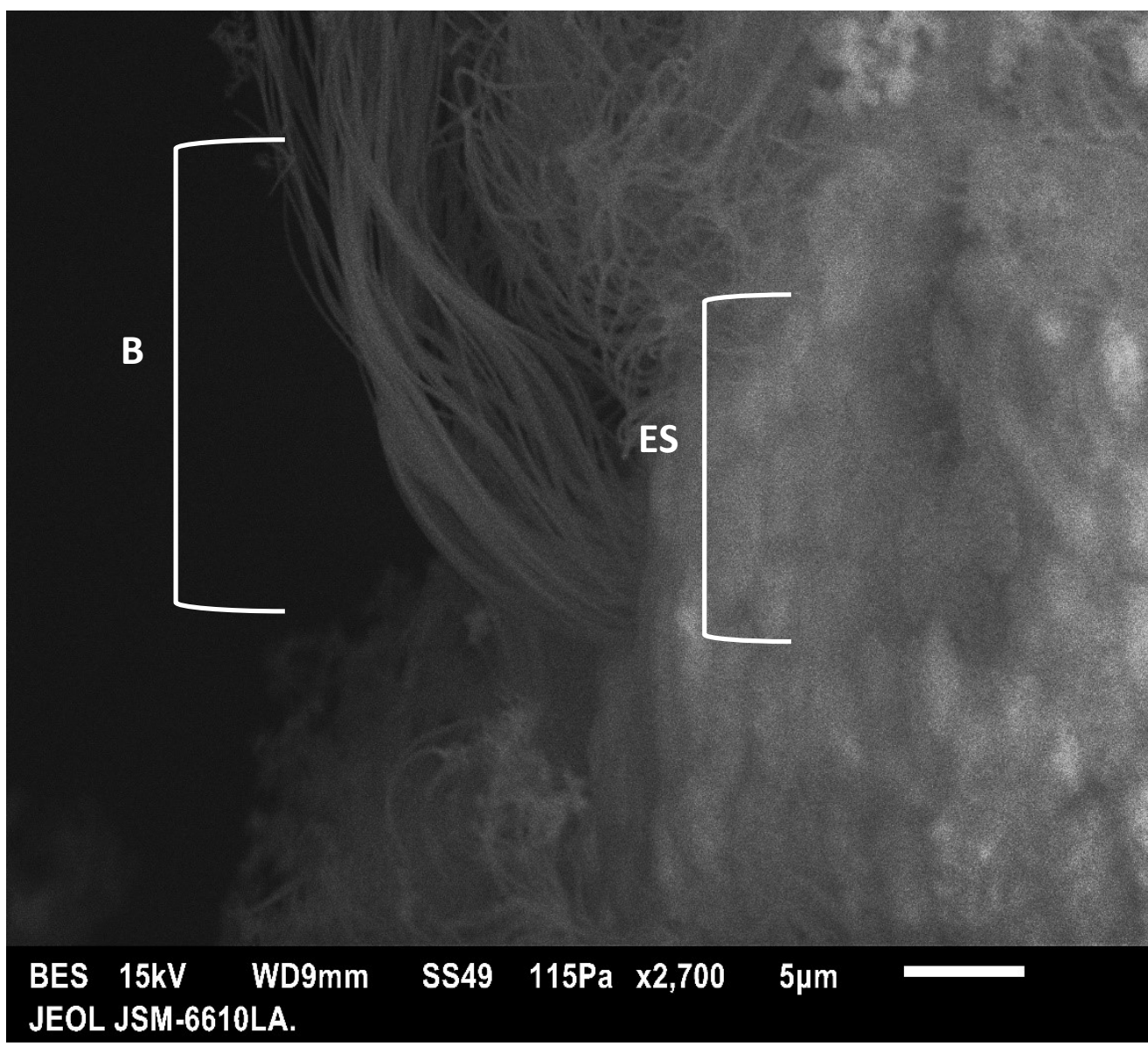

Figure 2.5 SEM image of a flagellar tuff (B)on a Watersipora subatra larvae. ES: eyespot

The putative sensory region contains the pyriform organ with long, bundled cilia called the vibratile plume (Figure 2.6 A-B) it is a densely packed group of slightly elongated cilia.

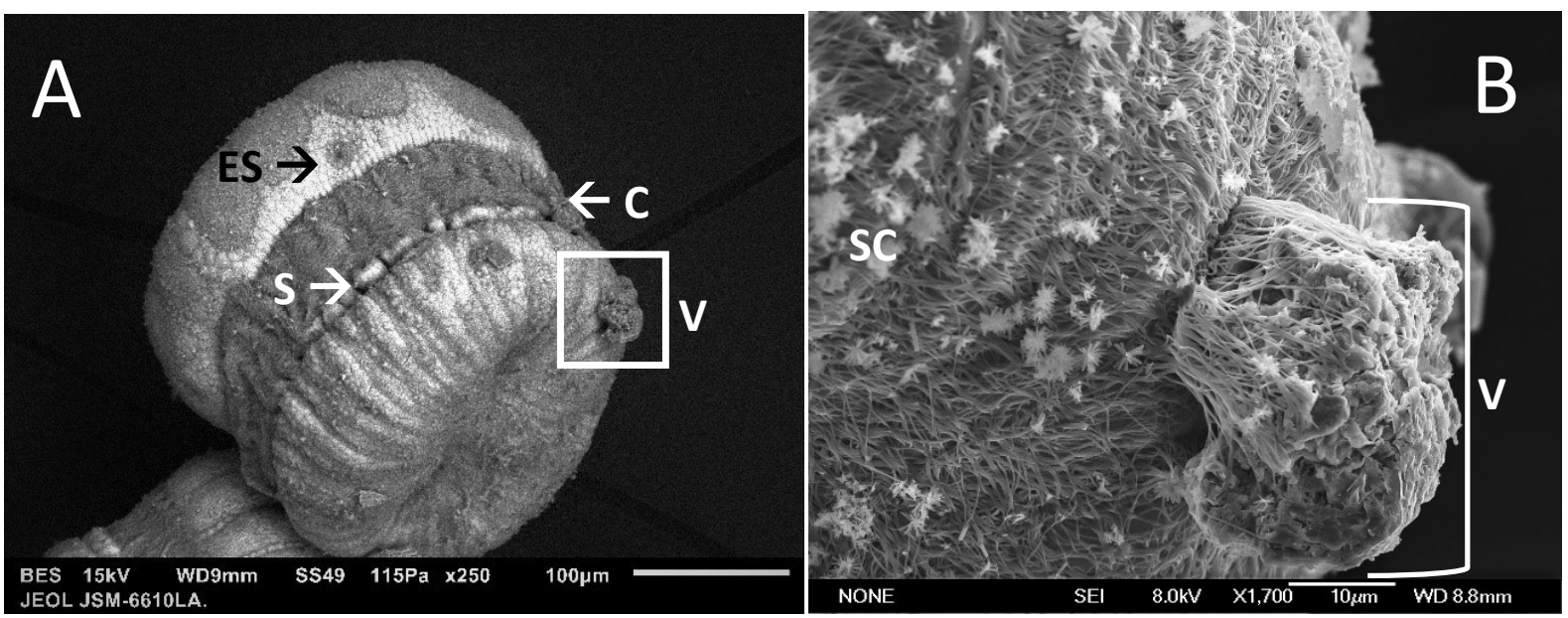

Figure 2.6 SEM images of Watersipora subatra larvae. V: vibratile plume; c: corona; ES: eyespot; s: supracoronal band; SC: salt crystals. 
In preparation for settlement the larva undergoes a "cleaving" in which the larva begins to split open (Figure 2.7A-C), this is to aid the metamorphosis stage of settlement. The cleavage begins from the opening of the internal sac and splits vertically along the oral hemisphere to the ciliated coronal band.

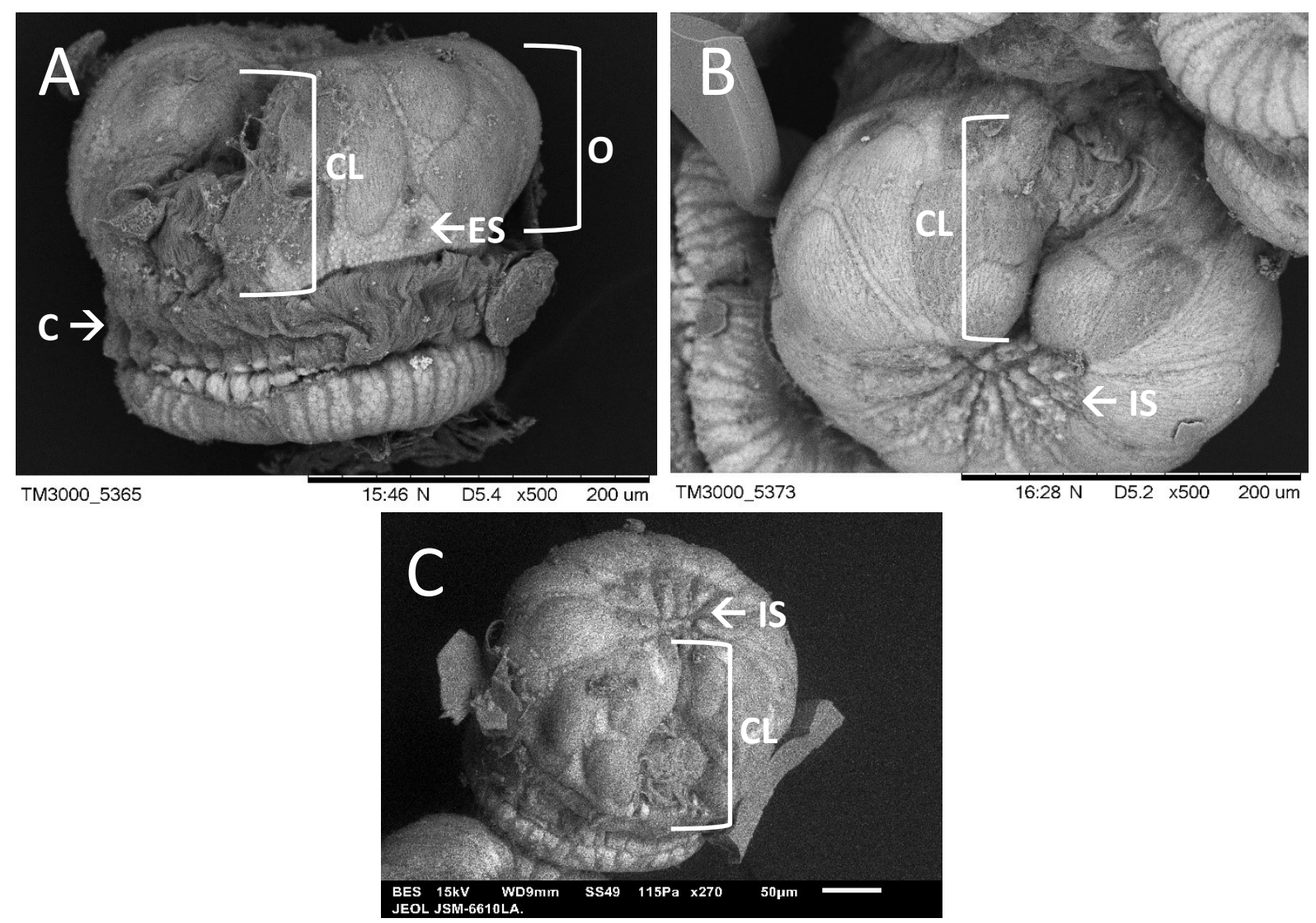

Figure 2.7 SEM images depicting the cleaving process (CL) of Watersipora subatra larvae. IS: opening to the internal sac; $\mathbf{O}$ : oral hemisphere; ES: evespot.

For settlement, the free-swimming larva undergoes catastrophic metamorphosis; the settled larva is unrecognisable compared to the free-swimming larvae (Figure 2.8A-B). The cilia and recognisable features are no longer present, and the larva takes on a roughly oval shape. The settled larva is blood-orange in colour and over a 24-hour period the ancestrula zooid develops. Figure 2.8A-B show a slightly raised mound in the centre of the settled larva which is the beginning of the ancestrula zooid. The settled larva is $\sim 400 \mu \mathrm{m}$ in length. 


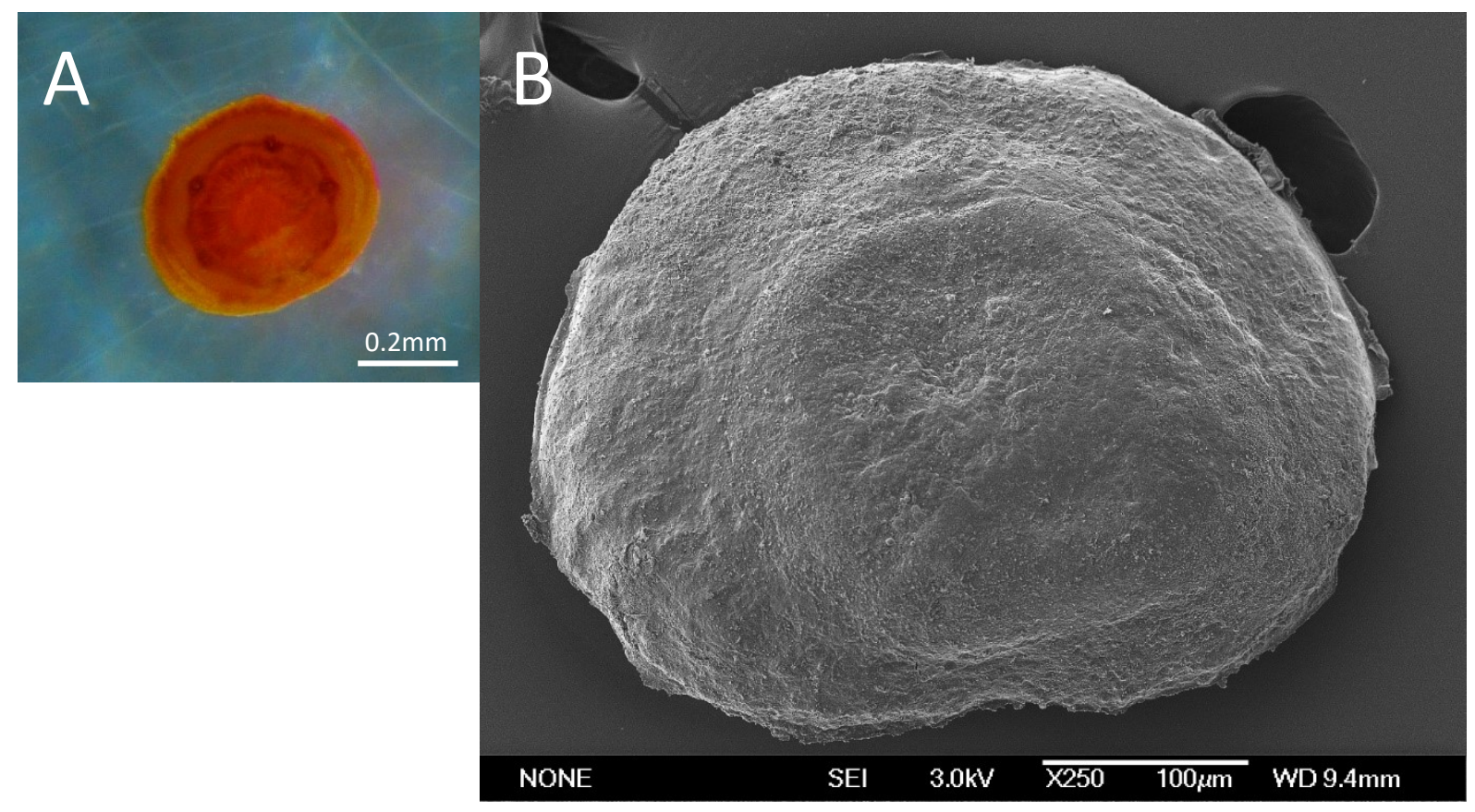

Figure 2.8 Settled Watersipora subatra larvae after metamorphosis. A, Light micrograph, B, SEM micrograph

Also note that due to the larvae being heavily ciliated it is difficult to remove all particles, and salt crystals are commonly visible in the SEM images. For additional SEM images of $W$. subatra larvae see appendix B. 


\subsection{Discussion}

Watersipora subatra larvae like other species in the Gymnolaemata class are coronate larvae with the three distinct regions (aboral and oral hemispheres and the corona band), and the class has the most morphologically diverse larvae of all bryozoans (Zimmer \& Woollacott, 1993; Gruhl, 2008). This diverse morphology is most likely due to the nonfeeding aspect of the larval stage as it allows the larva to invest energy into other endeavours that would otherwise be allocated to feeding. The lack of demand for feeding has seen larval traits evolving with a wider range of sensory and locomotive abilities; it has also allowed for the diversification of the nervous system (Reed \& Cloney, 1982; Santagata, 2008A).

The cilia of the coronal band beat orally to propel the aboral hemisphere forward into the environment in a spiral pattern, the larva can adjust the beating of the locomotive cilia to circumnavigate around objects it encounters (Reed, 1988). The movability of the larva around objects indicates that they have some sort of sensory mechanism to process its surroundings and to react accordingly. The apical disc located in the aboral hemisphere is the foremost part of the larva to be projected into the environment during the freeswimming stage and is considered an important sensory recipient for larval orientation (Reed et al., 1988; Santagata, 2008A). The apical disc varies in size depending on the species, it is quite predominant in the aboral hemisphere of $W$. subatra larva and this might indicate a greater input into assessing the external environment, substrate selection and hypothetically detecting sound. However, further investigation into the nervous system of W. subatra would be needed to support that hypothesis. The apical disc is formed at the aboral pole and consists of a neural plate and alternating bands of ciliated cells and unciliated, undifferentiated cells that radiate out from the neural plate and is an important sensory organ used for orientation during the free-swimming larval stage (Reed, 1988).

The pyriform organ is also thought to play an important role in habitat selection, it is connected to the apical disc by a neuro-muscular tract supporting this idea. The behaviour of the larvae during habitat selection also adds support, bryozoan larvae "crawl" along the substrate when looking for a suitable habitat location and will often re-enter the water column several times before settling. This behaviour displays that bryozoan larvae have substrate preferences and that they are possibly capable of interpreting biochemical cues 
associated with the desired/undesired substrate; $W$. subatra larvae observed in a petri-dish displayed this behaviour. While a larva is exploring a habitat, the pyriform is pushed against the substrate and the vibratile plume (a ciliated tuft of the pyriform organ) beats orally (at a slower rate than locomotive cilia) against the substrate (Reed, 1988; Reed et al., 1988). The vibratile plume has a vital role in habitat selection and is a specialised sensory organ used in identifying the larva's surroundings (Reed, 1987). It is possible that it could also have adapted to sensing vibrations caused by sound in the marine environment; however, due to the lack of research possible organs capable of detecting sound in bryozoans is currently speculation.

Another part of the larvae's sensory system consists of three different types of cells depending on their location relative to the locomotive cilia and their cilia morphology. Supracoronal cells are aborally located and line the corona; in the oral hemisphere, unciliated infracoronal cells create a band the corona; intercoronal cells are located adjacent to coronal cells (Santagata, 2008B). Intercoronal cells are related to the locomotion of the larvae, regulating the beating of the cilia of adjacent coronal cells through shared chemical synapses after receiving a stimulus, combining sensory and motor functions (Reed et al., 1988; Santagata, 2008B). The larvae of W. arcuata (closely related to W. subatra) have polymorphic intercoronal cells and appear more complicated compared to other bryozoan species, potentially elucidating that the cells have a wide range of functions (Zimmer \& Woollacott, 1989). It is likely that the intercoronal cells in W. subatra are similar to those of $W$. arcuata, however, because the coronal band is heavily ciliated the intercoronal cells were not visible in the SEM images. Interestingly in several gymnolaemata species, a serotonergic nervous system has been noted and is represented by a nerve ring around the corona and serotonergic cells (a nerve that is stimulated and releases serotonin) dispersed between the corona cells. The nervous system is related to both the apical organ and intercoronal cells and is probably linked to ciliary bands and musculature tissue through neural pathways. It is most likely related to either locomotion or metamorphosis, and the serotonergic cells are potentially a feature unique to the larvae of bryozoans; however, due to its redundancy after settlement, the larval nervous system is entirely lost during metamorphosis (Ghrul, 2009). 
Watersipora subatra larvae undergo "catastrophic metamorphosis" during their settlement stage, a process that is characteristic of gymnolaemata larvae. During metamorphosis, most of the larval organs and structures degenerate, with the cystid (body wall) and polypide (gut and tentacles) forming the ancestrula zooid. The cystid is derived from the pallial epithelium and internal sac, while it is thought that the polypide arises from either the apart of the apical disc or from the infracoronal cells (Zimmer \& Woollacott, 1989A). For settlement, the larvae will suddenly reverse the beating of their coronal cilia towards the aboral hemisphere, and this provides adequate force for the morphogenic movement required during metamorphosis (Reed, 1987). The internal sac is everted and, most of the larval organs and tissues disintegrate and the ancestrula zooid is formed in a second phase, the rapid change and dramatic loss of larval organs are why it is referred to as "catastrophic" (Santagata, 2008A; Gruhl, 2010).

Watersipora subatra larvae have demonstrated the ability to respond to external stimuli through phototaxic behaviour and crawling behaviour, therefore it is likely that they have the potential to detect and respond to sound. Numerous marine organisms and several marine larvae have displayed the ability either to avoid potential danger or to locate a suitable habitat. This chapter has shown that $W$. subatra have complex larvae that have evolved with a number of sensory organs and behavioural traits to respond to their environment and increase their survivability. With more research into their nervous system, structure and behavioural responses to sound it will be possible to elucidate whether they have the ability to detect sound. 


\section{Chapter 3: The effects of sound frequencies on the settlement behaviour of Watersipora subatra larvae}

\subsection{Introduction}

The role that natural underwater sound plays in several marine ecosystems and within individual species has been gaining recognition recently; most notable is the apparent influence of natural sound on the behaviour and settlement of the larvae of multiple marine species (Leis \& Lockett, 2005; Stanley et al. 2012; Butler et al., 2016; Menze et al., 2017). The settling larvae of several reef fish species have shown a direct behavioural response to sound when choosing a suitable habitat (moving towards reef sounds), whether they are responding to the sound of waves breaking on a reef or the sound created by invertebrates (stridulation) in a reef is debateable (Simpson et al., 2008; Parmentier et al., 2015).

Some coastal crustaceans, oysters and coral larvae move towards certain habitat sounds in situ indicating that local soundscapes could be an important settlement driver affecting the recruitment and survivability of several marine communities. Multiple coastal crab species move towards recorded reef sounds, suggesting that the trait could be wide spread in coastal crustaceans as well as a far-reaching influence on their ecology and recruitment success (Randford et al., 2007). The Crassostrea virginica oyster increased its levels of settlement in the presence of reef sounds demonstrating that the oyster larvae can use sound as an indicator of a suitable habitat, potentially increasing their survivability (Lillis et al., 2013). The larvae of a dominant reef building coral, Montastraea faveolata, showed an increase in settlement towards recorded reef sounds produced by fish and crustaceans implying that coral could potentially detect sound, but whether it is used in habitat selection or settlement behaviour remains largely unexplored (Vermeji et al., 2010). The role of sound in marine ecosystems could potentially threaten communities as anthropogenic sound pollution increases in the ocean (de Soto, 2016; Miksis-Olds, 2016). Interestingly an experiment examining effects caused by the sound of pile-driving on the larvae of Common sole and European sea bass indicated that the larvae were not affected by the sound (Bolle 
et al., 2016). These results suggest more research into individual species responses to anthropogenic sound is needed to understand larval responses to sound pollution.

As evidence for the importance of sound in the marine environment increases so does the concern for the effects of sound pollution within local and global marine ecosystems. The potential consequences could be wide-spread with varying degrees of effectiveness. With the possibility of altering behavioural patterns, foraging, mate and habitat selection, sound pollution could greatly affect the fitness of numerous marine species and should be considered as an important factor when examining ecosystems (Ranford et al., 2016). It is common knowledge that marine mammals especially cetaceans can be highly sensitive towards sound pollution. This has resulted in marine mammal impact assessments on the potential damage of anthropogenic sounds on these species (Myrberg, 1990; Donovan et al., 2017). As our dependence on the ocean for natural resources continues to grow, our sound pollution also continues to increase and will need to be carefully monitored to minimise potential effects on marine ecosystems. Sources of sound pollution, such as drilling and mining exploration, sonar, shipping lanes and seismic surveys are all obvious culprits. However, unusual sources of sound previously overlooked, exploring the characteristics of underwater sound and how to measure its environmental impact effectively need to be thoroughly investigated to have an adequate understanding of its role in the marine environment (Ainslie \& de Jong, 2016). Ironically scientific equipment used for locating and monitoring cetaceans such as echo sounders can potentially alter their diving behaviour and ultimately effect scientific results (Quick et al., 2017).

As we continue to expand our presence in the ocean we have increased the number of vessels and this has added to the sound pollution. The effects of anthropogenic sound are wide-spread and influence species differently, and it is therefore important to understand its interaction with marine ecosystems. There was no significant difference in the predator vigilance of Pagurus bernhardus the European common hermit crab in relation to vessel noise and controls (Nousek-McGregor \& Mei, 2016). However, it was noted that in the sound treatments the behavioural responses were more variable compared to the controls with the crabs taking longer to respond in the presence of shipping vessel sounds compared to just boat sounds or ambient ocean sounds. This demonstrates that different 
anthropogenic sounds can have different effects on behaviour (Nousek-McGregor \& Mei, 2016).

Small boats also contribute to sound pollution in reef fish larvae. Larval reef fish use the sounds of a reef when choosing a suitable settlement location, and reef noise therefore plays a significant role in the recruitment success of reef organisms. The increase of boat activities within the vicinity of reefs world-wide have the potential to affect the recruitment success of many organisms on a reef and ultimately their overall health and viability. Boat noise significantly reduced the settlement of juvenile Pomacentrus nagasakiensis and $P$. amboinensis, two common coral reef fish, compared to the settlement rate for ambient reef sounds. Ten other species were also examined however, due to their small sample sizes a significant result could not be obtained even though the trend does support the idea that boat noise with reef sounds reduces recruitment (Simpson et al., 2016). In a reef off the coast in Victoria, Australia, larval fish did not actively avoid boat sound and their ability to locate the ambient reef sounds was not affected; this implies that there might be reef fish species whose larvae are not influenced by sound and therefore reef recruitment may not be as largely affected by boat noise as thought (Jung \& Swearer, 2011).

Unexpectedly, both natural and anthropogenic sounds can promote biofouling on hulls (Stanley et al., 2016). Most large vessels produce sound (typically between $10-1000$ $\mathrm{Hz}$ ) within the biologically significant range for several marine organisms that could influence the settlement of fouling organisms (Götz et al., 2009; Stanley et al., 2016). The presence of vessel noise increased settlement, growth and development as well as reduced the mortality rate of several fouling marine organisms (Wilkens et al., 2012; McDonald et al., 2014; Stanley et al., 2014). This is an issue as biofouling is an expensive problem with a huge demand for research into environmentally-friendly, non-toxic alternatives to toxic antifouling paints, as they continue to be heavily restricted due to their impact on the environment.

Acting as vectors, small boats and larger vessels help promote the spread of nonnative, fouling species into new ecosystems world-wide, threatening local communities (Piola \& Conwell, 2010). While the invasive effects of fouling on large vessels is more apparent as they can transport fouling species all around the world via hulls or ballast water; smaller recreational boats can also add to the issue, with many fouling species able 
to survive being out of water for prolonged periods of time ( $>6$ hours), and species are able to migrate to locations previously unattainable (Kauano et al., 2017). A survey of thirty international transport vessels entering New Zealand waters found that vessels traveling trans-Tasman paths had increased fouling levels compared to other international vessels, and this could be due to the shorter trip, slower speeds and less extreme fluctuations in salinity and temperature. Increased biofouling does not necessarily equate to increased biosecurity risks, as many non-native species can have little to no effect on local ecosystems (Coutts \& Taylor, 2004). But it is important to develop environmental friendly preventive solutions to reduce fouling and decrease the success rate of non-native species establishing in new communities.

Several Bryozoan families are well known biofoulers, and many species therefore have global distributions (Gordon \& Matwatari, 1992). Arguably Watersipora subatra is the most common invasive species in the Watersiporidae family in New Zealand, Australia, Britain and California (Vieira et al., 2014). Similar to other species within this family, the endemic origins of $W$. subatra are unknown. Species within this family tend to display resilient tendencies to some toxic paints (Wisely, 1958). Watersipora subatra have nonfeeding, free-swimming larvae with a short larval stage, and because of this they can be indiscriminate when choosing their habitat for settlement making them very successful foulers (Zimmer \& Woolacott, 1989 B).

Biofouling is a complex subject with numerous factors influencing its severity. There are issues with current antifouling techniques, but it is clear there is no single solution to the problem. A holistic approach to fouling is the most effective way to gain a better understanding of the problem and to learn how these organisms respond to a wide range of stressors. The influence of anthropogenic sound on invertebrate larvae has been explored previously (Montgomery et al., 2006; de Soto, 2016) however, the effect of vessel noise on a fouling bryozoan species remains largely unexplored even though the phylum is one of the biggest contributors to biofouling. In this chapter I will explore the potential effects of sound on the larvae of $W$. subatra, a common fouling species in Wellington, New Zealand to increase the knowledge of the effect of anthropogenic sound within the marine environment with a focus on the issue of biofouling and potential environmental friendly solutions. 


\subsection{Methods}

\subsubsection{Larval collection and sound experiment}

Adult, reproductive colonies of $W$. subatra were collected from Chaffers Marina, Wellington ( $\left.41^{\circ} 17^{\prime} 18.9^{\prime \prime S} 174^{\circ} 47^{\prime} 06.1^{\prime \prime} \mathrm{E}\right)$ and were stored overnight in a large black storage container to avoid exposing the colonies to light. Adults were collected from pier E to increase the likelihood of the colonies being exposed to similar conditions and to increase relatedness (Fig. 3.1). An air pump was used to provide adequate aeration and water flow and the container was filled with unfiltered seawater to provide a natural food source. After 12 hours in darkness, the colonies were then exposed to an artificial light source (150W $200 \mathrm{~W}$ ) to induce larval release. This technique known as light shocking is used to trigger spawning in sexually mature bryozoans in the lab (Reed et al., 1988).

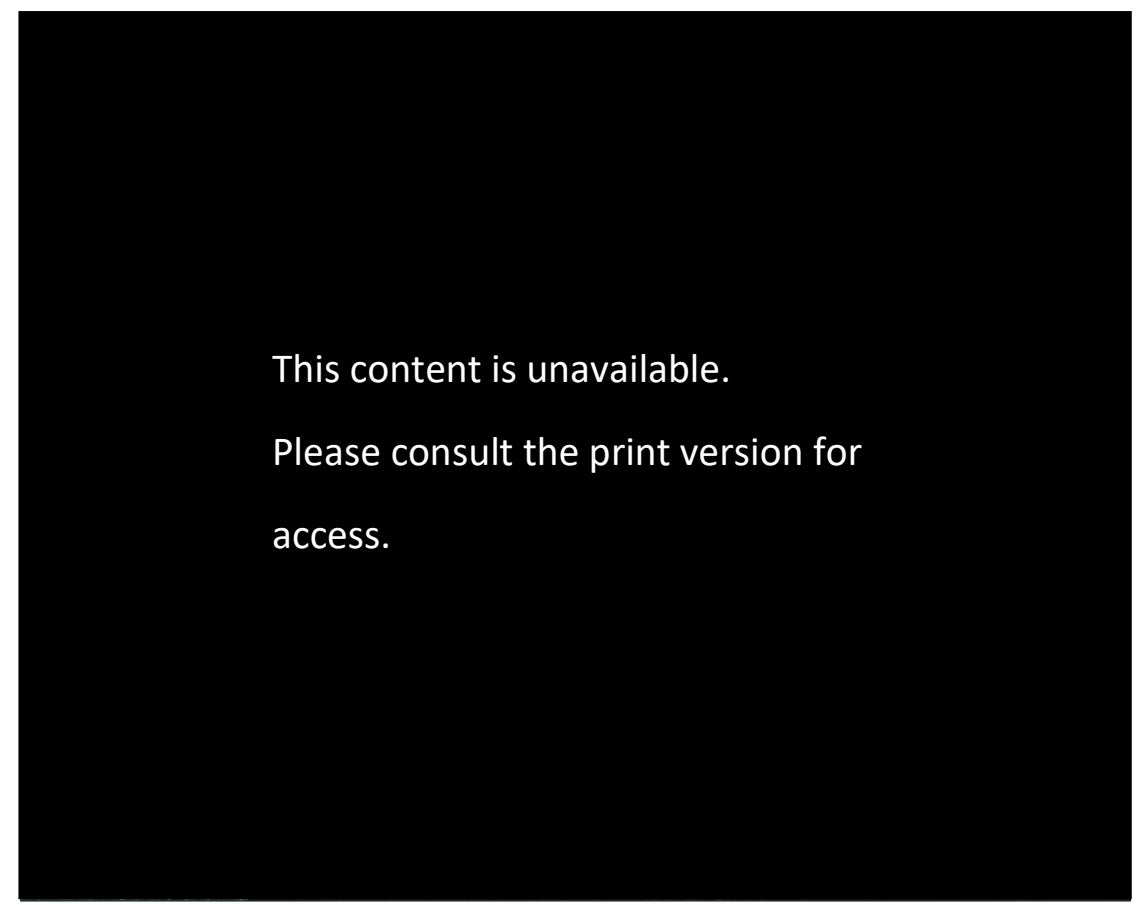

Figure 3.1 Satellite image of Chaffers marina, Wellington. E: indicates pier E, the collection site (Source: Google Images)

The free-swimming larvae were collected using a transfer pipette and kept in a petri dish with filtered sea water within the first hour of the adult colonies being exposed to a light source. This also allowed the random mixing of larvae from different colonies. The larvae were then randomly selected and pipetted into a single well of a $6 \times 4$ well plate until all wells contained a single larva (Fig. 3.2) $(n=24)$. The wells were filled with $3 \mathrm{~mL}$ of filtered seawater and the condition of the larvae were noted. The well plate was then randomly assigned a water bath, sound treatment and speaker and MP3 player. Well plates were then 


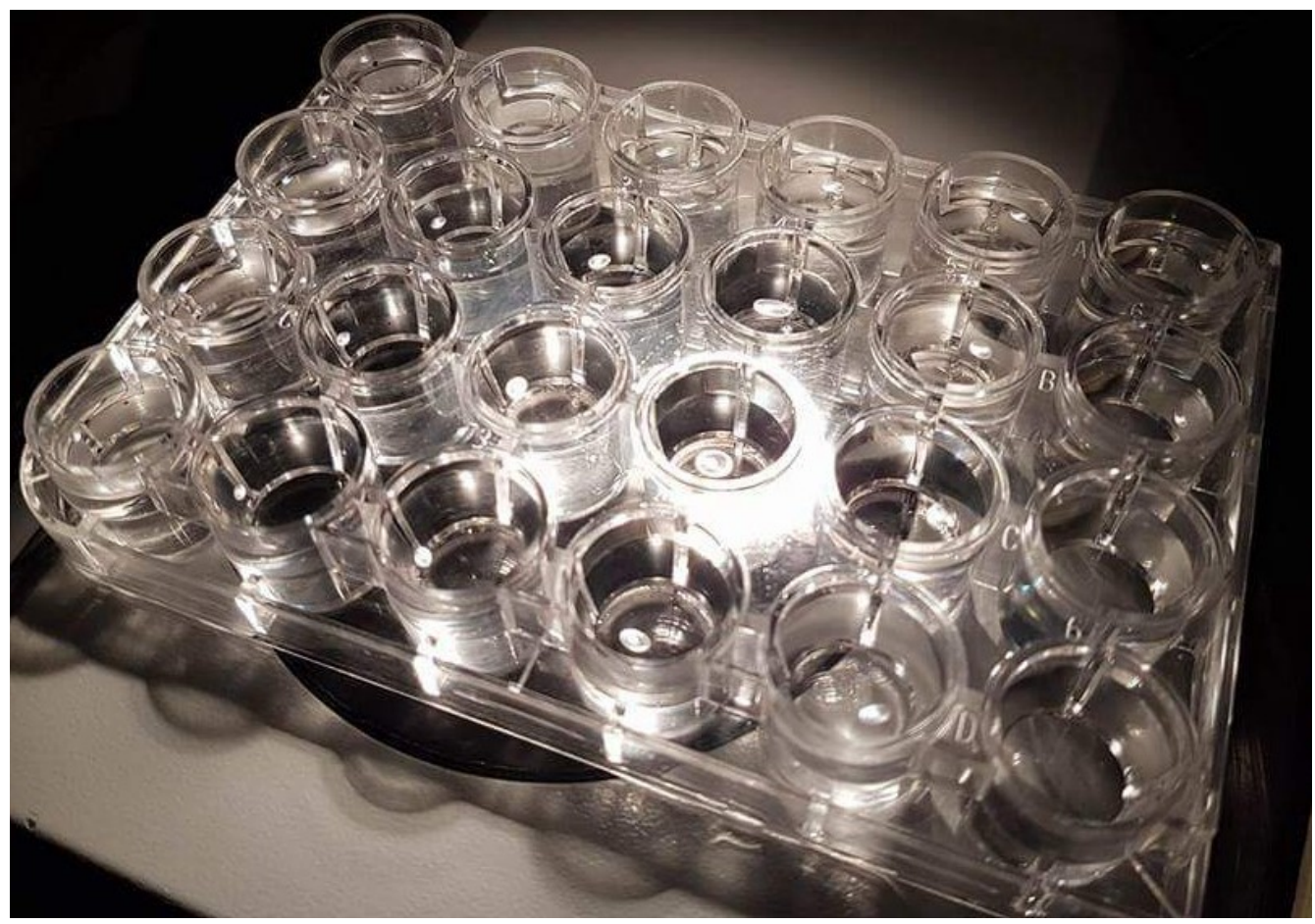

Figure 3.2. One larva was placed in each well of a $6 \times 4$ visually and acoustically transparent well plate

placed into their assigned water baths and the start time of the trial was noted, LED lights were used to reduce the chance of a temperature changed caused by lighting and to ensure a consistent light source was present to remove light as a potential confounding factor. Shade cloth was also used to cover the water baths for the same reason. The experiments were carried out in a temperature control room to reduce sound pollution from outside sources. During each exposure period the refrigerator unit was switched off to remove potential sound pollution. To check that temperature change did not affect the larvae during the trial, the temperature of the water baths was taken every 2 hours while the trial was running. Sound absorbing rubber mats were placed under the water baths to absorb any potential transferable acoustic energy from the environment. The experiment consisted of three sound treatments $(100 \mathrm{~Hz}, 500 \mathrm{~Hz}$ and $1000 \mathrm{~Hz})$ and a silent control. Nine water baths were used each time a trial was conducted, and the experiment was carried out seven separate times to ensure enough larvae were used in each treatment to reduce sampling bias and variance. The water baths acted as replicates for each treatment (see Fig. 3.3 for experiment setup). For each experimental run, each water bath was randomly assigned a treatment. The water baths were filled with 10 litres of fresh water to help maintain a consistent temperature in the well plates. In each water bath a speaker (Moki BassDisc Bluetooth Speaker, China, ACC-BDSCBK, $20 \mathrm{~Hz}-1 \mathrm{kHz}$ ) was randomly assigned and 
placed into a sealed waterproof plastic bag and was placed at the bottom of the water bath. Each speaker was randomly assigned a MP3 player (Sony NWZ-B183F 4GB mP3 FM Walkman music player, Japan), each set of speakers and MP3 players were randomly assigned a set treatment which was then calibrated for that set. Each treatment had 3 sets of speakers and MP3 players calibrated for the set frequencies, the MP3 players played a 60 -sec recording of the set frequency on a continuous loop during the experiment. For the silent control a speaker was placed in water bath but was not connected to a power source.

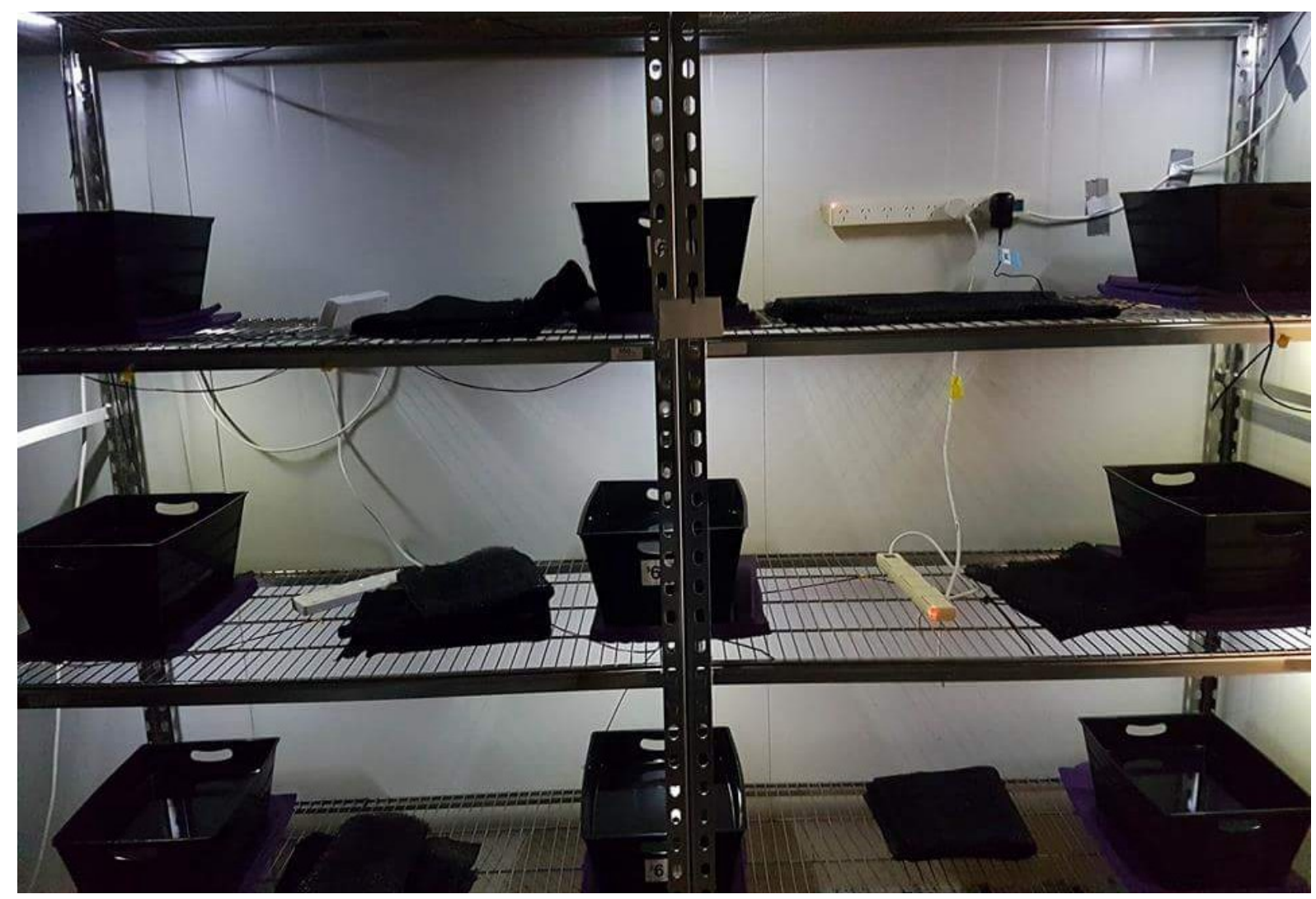

Figure 3.3 Water bath layout of sound experiment

During a trial, a well plate with a single larva in each well (24 individuals per water bath) was placed into a randomly assigned water bath and the start time was noted. Each individual in the well plate acts as a pseudo-replicate within the treatment. After the start of the experiment every two hours the well plate was removed from the water bath and the larvae in the well plates were observed under a dissecting microscope and the larval stage recorded for each larva. The three stages are free-swimming (in the water column), crawling (moving along the surface of the well) and settled (undergone metamorphosis), it was also noted if the larva was dead (no cilia movement, blackening of larva). A pipette was used to create a gentle current against a settled larva to confirm that it attached to the substrate. 
After a larva was recorded as settled, then further characterisation for that larva was stopped. Each trial was carried out over a 24-hour period as most larvae will settle within 12 hours of release. After this time, their survivability and the probability of being able to settle after 24-hours is highly reduced as they are non-feeding.

\subsubsection{Data analyses}

The Kruskal-Wallis comparisons of ranks test was used to test for a difference in the distribution of median settlement among the replicate water baths within the same treatment (each treatment was analysed separately). A Sharpiro-Wilk's test, the AndersonDarling normality test and Q-Q plots (Appendix B) were used to check the normality of the data. The rate of settlement was analysed using a linear mixed effects model to account for the variation caused by the different water baths within the treatments. All data analyses were performed using the software R Studio (Version 1.0.136), using the lme4 package (code and output are in appendix B).

Linear mixed-effects model formula:

$$
\begin{aligned}
\boldsymbol{y}=\boldsymbol{X} \boldsymbol{\beta}+\boldsymbol{Z} \boldsymbol{\gamma}+\boldsymbol{\varepsilon} \\
\boldsymbol{X}=\text { fixed effects } \\
\boldsymbol{\beta}=\text { fixed effects parameters } \\
\mathrm{Z}=\text { random variables } \\
\boldsymbol{\gamma}=\text { random effects parameters } \\
\boldsymbol{\varepsilon}=\text { error } \\
\boldsymbol{\gamma} \text { and } \boldsymbol{\varepsilon} \text { are independent }
\end{aligned}
$$




\subsection{Results}

The Kruskal-Wallis test revealed that the distribution of the median of settled larvae between the water baths within a treatment significantly differed for treatments two, three and the control group (Table 3.1). Boxplot A (Figure 3.4) shows that the median settlement time for most larvae across the water baths in the silent control group was within the first 5 hours however, in water baths D, F and G the median appeared to be higher. The boxplot also reveals three potential outliers in baths $A, B$ and $\mathrm{H}$; the upper and lower quartiles also vary across the water baths indicating that they do not have equal variance. Boxplot $B$ (Figure 3.1) shows that the median settlement time for larvae across the water baths in treatment one was between 5- 10 hours. There are 5 potential outliers within treatment one in the baths $A, D$ and $E$; the quartiles were uneven across the water baths suggesting unequal variances across the water baths in treatment one. Boxplot C (Figure 3.4) suggests that the median settlement time for larvae across the water baths in treatment two ranged from less than 5 hours up to 10 hours, with unequal variances due to the even quartiles across the baths. There are 4 potential outliers in treatment two in the baths $D, F$ and $G$. Boxplot D (Figure 3.4) indicates 3 potential outliers in water baths $A$ and $D$ within treatment three. The box plot indicates that the median settlement time for larvae across the water baths in treatment three varies up to 10 hours. Typical of the other treatments the uneven quartiles across the water baths indicate unequal variances across the baths in treatment three.

Table 3.1 Kruskal-Wallis comparisons of ranks for a difference in the distribution of median settlement time among the replicate water baths within the same treatment.

\begin{tabular}{|l|crrr|}
\hline Treatment & Kruskal-Wallis Chi-squared & df & \multicolumn{1}{c|}{$\boldsymbol{\alpha}$} & \multicolumn{1}{c|}{ p-value } \\
\hline Silent control & 37.779 & 8 & 0.01 & $8.27 e-06^{*}$ \\
Treatment one $(100 \mathrm{~Hz})$ & 12.746 & 6 & 0.01 & 0.05 \\
Treatment two $(500 \mathrm{~Hz})$ & 32.393 & 6 & 0.01 & $1.372 \mathrm{e}-05^{*}$ \\
Treatment three $(1000 \mathrm{~Hz})$ & 19.222 & 6 & 0.01 & $0.004^{*}$ \\
\hline
\end{tabular}




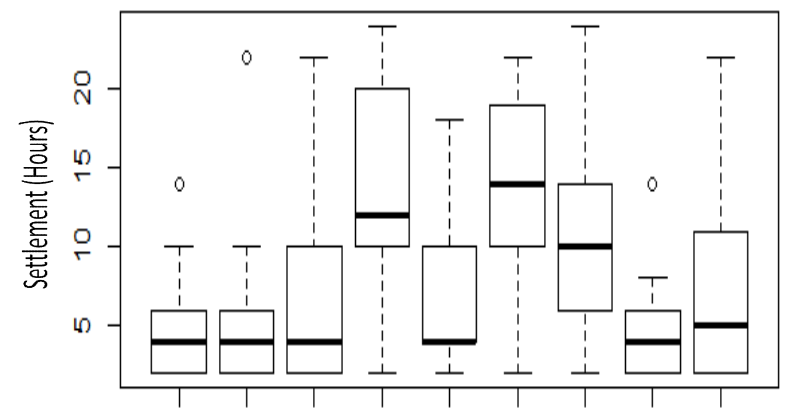

$\begin{array}{llllllllll}\text { A } & A & B & C & D & E & F & G & H & \text { I } \\ \text { Water baths in Silent Control } & \end{array}$

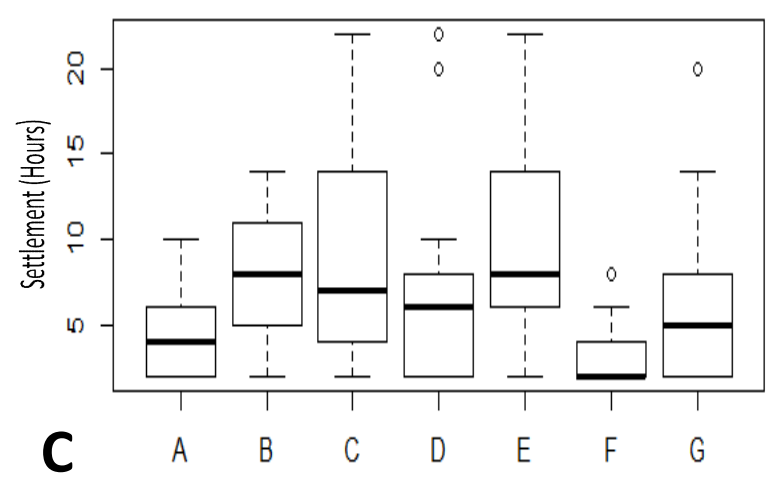

Water baths in Treatment Two $(500 \mathrm{~Hz})$

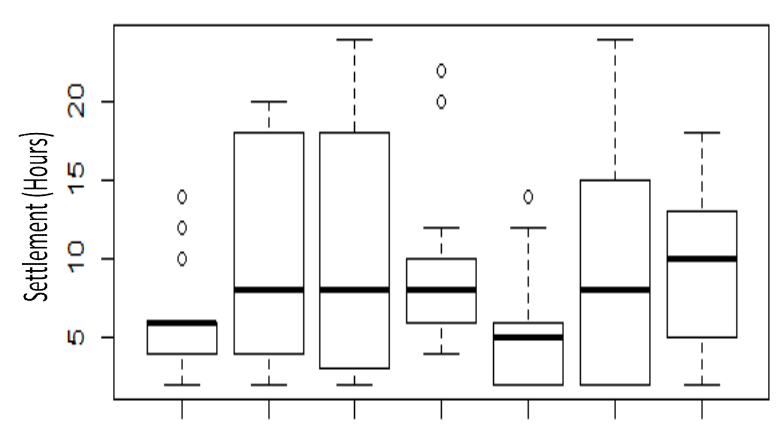

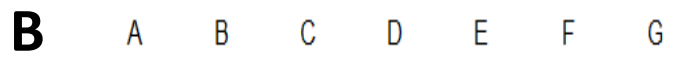

Water baths in Treatment one $(100 \mathrm{~Hz})$

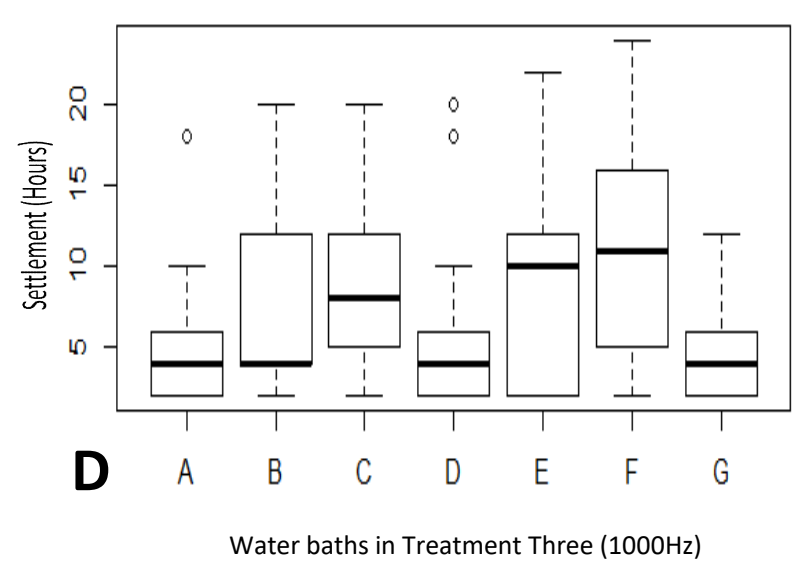

Figure 3.4 Boxplot of settlement time (Hours) of W supatra within each water bath for each treatment. A: Silent control; $\boldsymbol{B}$ : Treatment one; $\boldsymbol{C}$ : Treatment two; $\boldsymbol{D}$ : Treatment three. 
The Shapiro-Wilk's normality test was carried out on each individual treatment and control group as well the pooled data. The results (Table 3.2) show that the data does not have a normal distribution whether for each treatment or when pooled together. However, the Shapiro-Wilk's test can be weak against larger data sets as it is able to detect small deviations from the normality increasing the likelihood of the null hypothesis being rejected even if the data is mostly normal.

Table 3.2 Shapiro-Wilk's test for normality: $\boldsymbol{W}$-statistic, $\boldsymbol{\alpha}$ and $p$-value for data within each treatment and the pooled data set.

\begin{tabular}{|l|rrr|}
\hline Treatment & W statistic & $\boldsymbol{\alpha}$ & p-value \\
\hline Silent control & 0.838 & 0.05 & $1.663 \mathrm{e}-13^{*}$ \\
Treatment one $(100 \mathrm{~Hz})$ & 0.887 & 0.05 & $7.017 \mathrm{e}-09^{*}$ \\
Treatment two $(500 \mathrm{~Hz})$ & 0.826 & 0.05 & $5.229 \mathrm{e}-12^{*}$ \\
Treatment three $(1000 \mathrm{~Hz})$ & 0.839 & 0.05 & $2.089 \mathrm{e}-11^{*}$ \\
Pooled data set & 0.849 & 0.05 & $<2.2 \mathrm{e}-16^{*}$ \\
\hline
\end{tabular}

The Anderson-Darling normality test was therefore also carried out on the data of each treatment and the pooled dataset, using the null hypothesis that the data comes from a normal distribution. The results of the analysis (Table 3.3) were comparable to those of the Shapiro-Wilk's test, in that the tests for each treatment and the pooled data failed to accept the null hypothesis suggesting that the data for each treatment and the pooled data did not come from a normal distribution. See Appendix B for Q-Q plots of pooled data and data for each treatment.

Table 3.3 The Anderson-Darling test for normality: A-D-statistic, $\alpha$ and $p$-value for data within each treatment and the pooled data set.

\begin{tabular}{|l|rlr|}
\hline Treatment & A-D statistic & $\boldsymbol{\alpha}$ & p-value \\
\hline Silent control & 10.968 & 0.05 & $<2.2 \mathrm{e}-16^{*}$ \\
Treatment one $(100 \mathrm{~Hz})$ & 4.957 & 0.05 & $2.543 \mathrm{e}-12^{*}$ \\
Treatment two $(500 \mathrm{~Hz})$ & 8.063 & 0.05 & $<2.2 \mathrm{e}-16^{*}$ \\
Treatment three $(1000 \mathrm{~Hz})$ & 8.308 & 0.05 & $<2.2 \mathrm{e}-16^{*}$ \\
Pooled data set & 31.692 & 0.05 & $<2.2 \mathrm{e}-16^{*}$ \\
\hline \multicolumn{3}{|c}{$*$ Statistically significant p-value }
\end{tabular}

The average mean settlement times (hours) of $W$. subatra and their standard errors were calculated for each treatment group (Figure 3.5), showing that the mean settlement time was not significant across the treatments (Table 3.4). Treatment two may have a shorter settlement mean compared to the other treatments, although the standard errors for each treatment overlap (Table 3.4). 
Table3.4 Summary of mean settlement times ( $h$ ) of larvae in each treatment with standard errors, $t$-values and p-values.

\begin{tabular}{|l|rrrr|}
\hline Treatment & Mean settlement time & Standard error & t-value & p-value \\
\hline Silent control & 7.977 & 0.885 & 9.01 & 1 \\
Treatment one $(100 \mathrm{~Hz})$ & 8.331 & 1.346 & 0.263 & 0.604 \\
Treatment two $(500 \mathrm{~Hz})$ & 6.954 & 1.340 & -0.763 & 0.223 \\
Treatment three $(1000 \mathrm{~Hz})$ & 7.596 & 1.341 & -0.284 & 0.388 \\
\hline
\end{tabular}

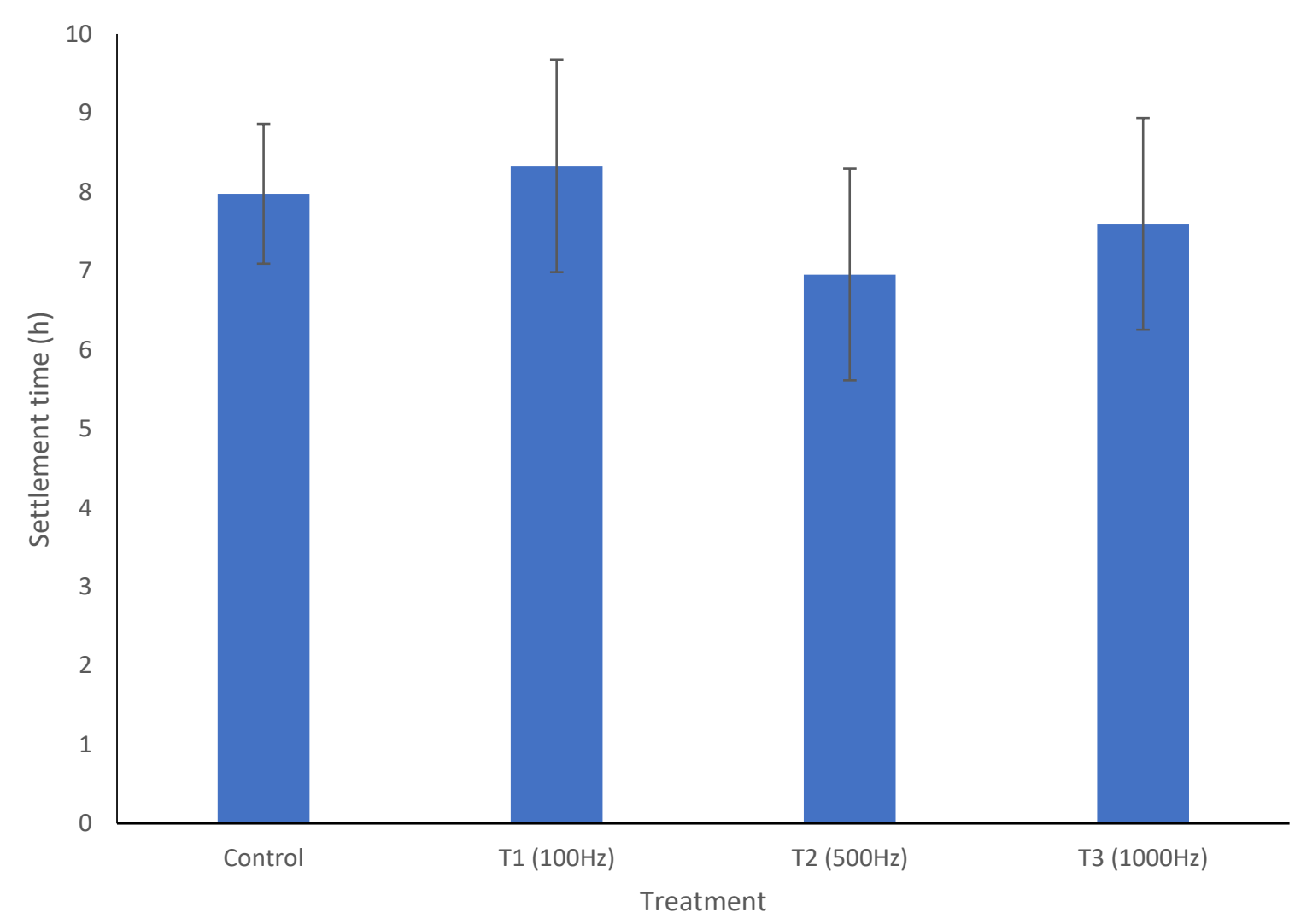

Figure 3.5 Mean settlement times (h) with standard error bars for W. subatra larvae in each treatment. T1: Treatment one; T2: Treatment two; T3: Treatment three.

The proportion of settled larvae over the 24-hour period for each treatment is illustrated in Figure 3.6. The graph suggests that the proportion of settling larvae within treatment one in the first 8 hours was noticeably less compared to the other treatments however the proportion of settled larvae is very similar at the end of the 24-hour period (Table 3.5), treatment one also has the lowest overall percentage (84.2\%) of settled larvae at the end of the experiment. 
Table 3.5 Summary of settled and unsettled larvae in each treatment at the of the 24-hour experiment period.

\begin{tabular}{|l|r|r|rc|}
\hline \multirow{2}{*}{ Treatment } & \multicolumn{2}{|c|}{ Settled } & \multicolumn{2}{c|}{ Unsettled } \\
\cline { 2 - 5 } & N & Percent & N & Percent \\
\hline Control & 196 & $92 \%$ & 17 & $8 \%$ \\
Treatment one $(100 \mathrm{~Hz})$ & 139 & $84.2 \%$ & 26 & $15.8 \%$ \\
Treatment two $(500 \mathrm{~Hz})$ & 149 & $89.2 \%$ & 18 & $10.8 \%$ \\
Treatment three $(1000 \mathrm{~Hz})$ & 147 & $88.6 \%$ & 19 & $11.4 \%$ \\
\hline
\end{tabular}

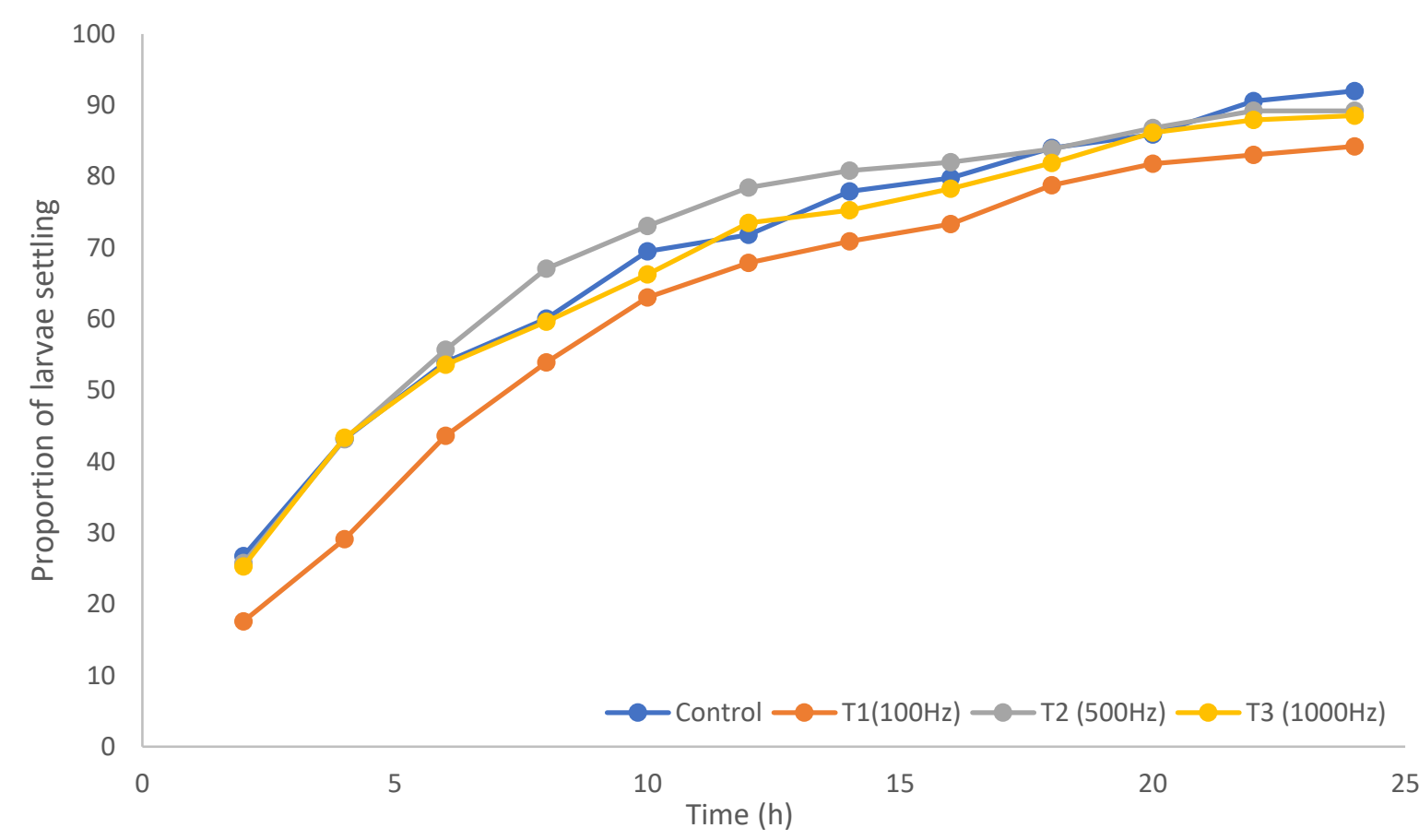

Figure 3.6 Proportion (\%) of settling W. subatra larvae over time (h) for each Treatment. T1: Treatment one; T2: Treatment two; T3: Treatment three.

Due to the variability between the water baths within each treatment shown in the boxplots (Figure 3.4), the potential effects of the water baths will need to be taken into consideration. A linear mixed-effects model is most suitable as it factors in fixed-effect parameters and random-effects (unobserved random variables), and the effect of the water baths within the treatments can be incorporated as a random-effect.

The analysis was carried out using the Restricted Maximum likelihood criterion (REML) to fit the data to the model as REML is an unbiased estimator of the variance in the model. The analysis was also carried out using the Maximum Likelihood criterion (ML) to fit 
the model. The variance of settled larvae as a random effect was estimated at $1.731 \mathrm{e}-12$ hours $^{2}$ in the REML fit with a standard deviation of $1.731 \mathrm{e}-06$ hours. Using the ML fit the estimated variance and standard deviation was 0 , this indicates that the level of "betweengroup" variance is not adequate to incorporate random effects into the model, therefore the REML fit is a more suitable choice for the model. Using the t-values acquired from the REML mixed-effects model the p-values (Table 3.4) were calculated for each of the treatment groups in RS Studio (see appendix B for code), using n-1 to calculate the degrees of freedom. The settlement time of $W$. subatra larvae was not statistically significant across the different treatments with $95 \%$ confidence. 


\subsection{Discussion}

The results of the sound experiment, while not statistically significant are still interesting and opens the way for more experiments into the effects of sound on bryozoan larvae. As expected the data was not normally distributed as the larvae do not settle evenly across the 24-hour period, the non-feeding larvae tend to settle relatively quickly before they run out of their yok. As expected the proportion of larvae settling was highest within the first 8-hours, the incline of the data for each treatment in Figure $\mathbf{3 . 6}$ was steepest in that time frame before gradually levelling out after the 10-hour mark.

The $100 \mathrm{~Hz}$ sound treatment did demonstrate a slight trend of delaying settlement, even though it was not statistically significant. However, treatment one had the lowest proportion of settled larvae consistently throughout the experiment with only $84.2 \%$ of larvae settling at the end of the experiment compared to the $92 \%$ of larvae that settled in the silent control group (Table 3.5). The $100 \mathrm{~Hz}$ treatment also had the highest mean settlement time $(8.3 \mathrm{~h} \pm 1.346)$ even if it overlapped with the other treatments. These trends for treatment one are interesting as they suggest that the lower frequency $(100 \mathrm{~Hz})$ has the potential to not only delay settlement but to also reduce the number of settling larvae. This trend should be explored more thoroughly as the survivability of $W$. subatra larvae into adulthood is greatly influenced by locating a suitable habitat before their yolk sac diminishes; so delaying settlement can reduce their ability to undergo metamorphosis. The development of the adult colony could potentially be affected by settlement delay, similarly to the reduced tentacle crown size seen in Bugula neritina post-settlement delay (Burgess \& Marshall, 2011). The potentially reduced overall number of settling larvae at this frequency is also interesting as it also lowers the ability of $W$. subatra to establish itself in a new environment. Hypothetically reducing the percentage of settling W. subatra larvae in a harbour from $92 \%$ to $84 \%$ (Table 3.5 ) could significantly reduce their presence and reduce the possibility of spreading to new vessels, however, their biomass in the ecosystem would need to be estimated to assess if it would have an impact. While in this sound experiment $100 \mathrm{~Hz}$ did not differ significantly from the other treatments, it shows potential to delay and reduce settlement in $W$. subatra larvae which further investigation can elucidate and could potentially be a novel solution to reducing $W$. subatra biofouling. 
An unexpected effect on the settlement rate was the variation of settlement between the water baths within each treatment. There are a lot of potential unknown factors that could have affected the settlement rate between the water baths.

The results of the experiment are still intriguing as it provides further insight into the ecology and morphological abilities of W. subatra. Future experiments would need to be conducted to help ascertain if $W$. subatra and other bryozoan larvae are influenced by sound in the marine environment whether it is natural or anthropogenic. Additional investigation will help determine if sound has the potential to attract or deter bryozoan larvae, although with the slight response to the $100 \mathrm{~Hz}$ treatment and a previous research suggesting that bryozoan larvae respond to vessel noise (Stanley et al., 2014) it is more likely that bryozoans will have the ability to respond to sound even if only slightly. 


\section{Chapter 4: Overview, discussion and future prospects?}

\subsection{Overview}

Chapter two examined the morphological traits and behaviour of $W$. subatra larvae to improve our understanding of their ecology and life histories. Observations of freeswimming behaviour and SEM images have shown that $W$. subatra have a complex morphology and a diverse range of sensory organs capable of interacting and responding to the surrounding environment. Because $W$. subatra larvae displays behavioural responses to outside stimuli, it is possible that they possess sensory organs that can respond to sound. It is possible as they are not expending energy for feeding and digesting, so they potentially can assign energy to the development of other sensory organs.

The sound experiment in chapter three examining $W$. subatra larval response to different frequencies produced conflicting results. There was no significant difference in settlement times for larvae between the silent control, $100 \mathrm{~Hz}, 500 \mathrm{~Hz}$ and $1000 \mathrm{~Hz}$, suggesting that $W$. subatra larvae might not respond to sound. However, there is a possible delay and reduction in settlement when exposed to the $100 \mathrm{~Hz}$ frequency. Larvae settling in the $100 \mathrm{~Hz}$ treatment took slightly longer to settle compared to the silent control and the $500 \mathrm{~Hz}$ and $1000 \mathrm{~Hz}$. The overall number of settling larvae was also lower in the $100 \mathrm{~Hz}$ treatment as opposed to the other treatments. Bryozoan species in other sound experiments have also demonstrated the potential to respond to sound (Stanley et al., 2014). These conflicting results make it difficult to extrapolate any substantial evidence either for or against $W$. subatra ability to respond to sound; it does highlight the need to conduct further investigations into the possible effect sound has on bryozoan larvae.

The complex larval morphology implies the potential for sound sensing organs, which is somewhat evident in the settlement behaviour of larvae in $100 \mathrm{~Hz}$ treatment. Although it is not enough for the behaviour to differ significantly from the other sound treatments. This suggests that if $W$. subatra larvae did respond to sound it's influence on the behaviour of the larvae is so minor it doesn't have a noticeable impact.

The lack of evidence in the sound experiment may be due to unknown factors not taken into account in the experimental set up. It is possible that the water baths were not spaced out enough to completely reduce the sound transference from the surrounding 
baths. The temperature control room where the experiment was conducted was located in the wet lab, where there was quiet a lot of noise pollution, it is possible that the isolation was not enough to remove the external sounds. If the exclusion of sound pollution was not sufficient it is possible that the silent control was not truly silent and therefore not an unbiased control.

It is also possible that seasonal changes during the experimental period affected the results. Although a possible long-term experiment only examining settlement rates over a long-time scale would most likely be the best way to determine if seasonal change has an effect on settlement rate. Adding a wider range of frequencies may also provide a differing result, as the larvae may only respond to higher frequencies (possibly $>10,000 \mathrm{~Hz}$ ). The type of sound recording could have played a role, and comparing natural sounds (waves on a reef) to anthropogenic sounds (vessel engine, sonar) could provide knowledge into whether bryozoan larvae use natural sounds to orientate themselves or if they are being influenced by anthropogenic sounds.

Increasing the number of the sample size would decrease the variance and produce more accurate results that are more representative of the population. Comparing $W$. subatra to other bryozoan species in other classes might reveal differences in evolutionary trends and the phylogeny within the phylum. Changing the experimental design into a twoway ANOVA to examine the effects sound and temperature have and how they interact with each other would be enlightening and will show a more realistic result. Preliminary tests looking at increasing temperature while being exposed to different sound frequencies does appear to affect the settlement and mortality rate. Continuing this experiment design would produce interesting and informative results.

In conclusion $W$. subatra is an important biofouler and increasing our knowledge on their life histories will contribute to formulating more effective and holistic antifouling products and procedures. Their larvae are intricate and utilise a range of sensory organs and behavioural responses when interacting with their surrounding environment. They have demonstrated a possible potential to respond to sound, although further research is needed to elucidate the relationship $W$. subatra larvae has with underwater sound. 


\section{References}

Ainslie, M. A., \& de Jong, C. A. (2016). "Sources of underwater sound and their characterization." The Effects of Noise on Aquatic Life II, Springer: 27-35.

Al-Naamani, L., Dobrestov, S., Dutta, J., \& Burguss, J.G. (2017). "Chitosan-zinc oxide nanocomposite coatings for the prevention of marine biofouling." Chemosphere 168: 408417.

Allen, J. D. \& Pernet, B. (2007). "Intermediate modes of larval development: bridging the gap between planktotrophy and lecithotrophy." Evolution \& development 9(6): 643-653.

Almeida, E., Diamantino, T. C., \& de Sousa, O. (2007). "Marine paints: The particular case of antifouling paints." Progress in Organic Coatings 59: 2-20.

Alzieu, C. (2000). "Environmental impact of TBT: the French experience." Science of the Total Environment 258(1): 99-102.

Andrew, R. K., Howe, B. M., \& Mercer, J.A. (2011). "Long-time trends in ship traffic noise for four sites off the North American West Coast." The Journal of the Acoustical Society of America 129(2): 642-651.

Andrew, R. K., Howe, B. M., Mercer, J.A. \& Dzieciuch, M. A. (2002). "Ocean ambient sound: comparing the 1960s with the 1990s for a receiver off the California coast." Acoustics Research Letters Online 3(2): 65-70.

Ashokan, M., Latha, G., Thirunavukkarasu, A., Raguraman, G. \& Venkatesan, R. (2016). "Ice berg cracking events as identified from underwater ambient noise measurements in the shallow waters of Ny-Alesund, Arctic." Polar Science 10(2): 140-146.

Azemar, F., Fay, F., Rehel, K., \& Linossier, I. (2015). "Development of hybrid antifouling paints." Progress in Organic Coatings 87: 10-19. 
Bax, N., Williamson, A., Aguero, M., Gonzalez, E., \& Greeves, W. (2003). "Marine invasive alien species: a threat to global diversity." Marine Policy 27: 313-323.

Bolle, L. J., de Jong, C. A., Bierman, S. M., van Beek, P. J., Wessels, P. W., Blom, E. van Damme, C. J., Winter, H. V., \& Dekeling, R.P. (2016). “Effect of pile-driving sounds on the survival of larval fish." The Effects of Noise on Aquatic Life II, Springer: 91-100.

Brine, O., Hunt, L., \& Costello, M. J. (2013). "Marine biofouling on recreational boats on swing moorings and berths." Management of Biological Invasions 4(4): 327-341.

Burgess, S. C., Hart, S. P., \& Marshall, D. J. (2009). "Pre-settlement Behavior in Larval Bryozoans: The Roles of Larval Age and Size." Biological Bulletin 216: 344-354.

Burgess, S. C., \& Marshall D. J. (2011). "Field estimates of planktonic larval duration in a marine invertebrate." Marine Ecology Progress Series 440: 151-161.

Buskens, P., Wouters, M., Rentrop, C., \& Vroon, Z. (2013). "A brief review of environmentally benign antifouling and foul-release coatings for marine applications." Journal of Coatings Technology and Research 10(1): 29-36.

Butler, J., Stanley, J. A., \& Butler, M. J. (2016). "Underwater soundscapes in near-shore tropical habitats and the effects of environmental degradation and habitat restoration." Journal of Experimental Marine Biology and Ecology 479: 89 - 96.

Cancino, J. M., \& Gallardo, J. A. (2000). "Effects of Light On Bryozoan Larval Settlement." 11th International Bryozoology Association Conference: 168-175.

Cancino, J. M., \& Gallardo, J. A. (2004). "Effects of delayed settlement in life expectancy of the bryozoan Bugula flabellata (Bryozoa: Gymnolaemata)." Chilean Journal of Natural History 77(2): 1-6. 
Chapman, N. R., \& Price, A. (2011). "Low frequency deep ocean ambient noise trend in the Northeast Pacific Ocean." The Journal of the Acoustical Society of America 129(5): EL161EL165.

Choi, C. H., Scardino, A. J., Dylejko, P. G., Fletcher, L. E., \& Juniper, R. (2013). "The effect of vibration frequency and amplitude on biofouling deterrence." Biofouling 29(2): 195-202.

Clay, T., \& Grünbaum, D. (2010). "Morphology-flow interactions lead to stage-selective vertical transport of larval sand dollars in shear flow." Journal of Experimental Biology 213(8): 1281-1292.

Cohen, A. (1979). "Critical point drying-principles and procedures." Scanning electron microscopy: 303-324.

Corbett, J. J., Winebrake, J., Comer, B., \& Green, E. (2011). "Energy and GHG emissions savings analysis of fluoropolymer foul release hull coating." Energy and Environmental Research Associates, LLC.

Coutts, A. D., \& Taylor, M. D. (2004). "A preliminary investigation of biosecurity risks associated with biofouling on merchant vessels in New Zealand." New Zealand Journal of Marine and Freshwater Research 38(2): 215-229.

Davis, K., \& Marshall, D. J. (2014). "Offspring size in a resident species affects community assembly." Journal of Animal Ecology 83: 322-331.

de Soto, N. A. (2016). "Peer-Reviewed Studies on the Effects of Anthropogenic Noise on Marine Invertebrates: From Scallop Larvae to Giant Squid." The Effects of Noise on Aquatic Life II. A. N. Popper and A. Hawkins. New York, NY, Springer New York: 17-26.

Dingeldein, A. L., \& White, J. W. (2016). "Larval traits carry over to affect post-settlement behaviour in a common coral reef fish." Journal of Animal Ecology 85(4): 903-914. 
Dobretsov, S., Abed, R. M., \& Teplitski, M. (2013). "Mini-review: Inhibition of biofouling by marine microorganisms." Biofouling 29(4): 423-441.

Dobretsov, S., \& Qian, P-Y. (2006). "Facilitation and inhibition of larval attachment of the bryozoan Bugula neritina in association with mono-species and multi-species biofilms." Journal of Experimental Marine Biology and Ecology 333(2): 263-274.

Donald, R. (1976). “Mechanics of Underwater Noise." New York: Pergamon Press.

Donovan, C. R., Harris, C. M., Milazzo, L., Harwood, J., Marshall, L., \& Williams, R. (2017). "A simulation approach to assessing environmental risk of sound exposure to marine mammals." Ecology and evolution 7(7): 2101-2111.

Eggleston, D. B., Lillis, A. \& Bohnenstiehl, D. R. (2016). "Soundscapes and larval settlement: larval bivalve responses to habitat-associated underwater sounds." The Effects of Noise on Aquatic Life II, Springer: 255-263.

Fässler, S. M., Payne, M. R., Brunel, T., \& Dickey-Collas, M. (2011). "Does larval mortality influence population dynamics? An analysis of North Sea herring (Clupea harengus) time series." Fisheries Oceanography 20(6): 530-543.

Fisher, R. \& Bellwood, D. R. (2003). "Undisturbed swimming behaviour and nocturnal activity of coral reef fish larvae." Marine Ecology Progress Series 263: 177-188.

Fitridge, I., Dempster, T., Guenther, J., \& de Nys, R. (2012). "The impact and control of biofouling in marine aquaculture: a review." Biofouling 28(7): 649-669.

Frisk, G. V. (2012). "Noiseonomics: The relationship between ambient noise levels in the sea and global economic trends." Scientific reports 2: 437.

Fusetani, N. (2004). "Biofouling and antifouling." Natural Product Reports 21(1): 94-104. 
Garcia, M., Stupak, M., Perez, M., \& Blustein, G. (2015). "Transitioning to nontoxic antifouling paints." Pigment and Resin Technology 44(2): 116-121.

Garrison, L. P. (1999). "Vertical migration behavior and larval transport in brachyuran crabs." Marine Ecology Progress Series 176: 103-113.

Gordon, D. P. (2003). “Living Lace.” New Zealand Geographic: 81-95.

Gordon, D. P. (2010). “Phylum Bryozoa.” New Zealand Coastal Marine Invertebrates. Canterbury University Press.

Gordon, D. P., \& Matwatari, S. F. (1992). "Atlas of marine-fouling Bryozoa of New Zealand ports and harbours." New Zealand Oceanographic Institute Miscellaneous Publication 107: 1-52.

Gordon, D. P., Ramalho, L. V., \& Taylor, P. D. (2006). "An unreported invasive bryozoan that can affect livelihoods-Membraniporopsis tubigera in New Zealand and Brazil." Bulletin of Marine Science 78(2): 331-342.

Gordon, D. P., Taylor, P. D., \& Bigey, F. P. (2009). "Phylum Bryozoa: moss animals, sea mats, lace corals. New Zealand inventory of biodiversity." Volume One: Kingdom Animalia: Radiata, Lophotrochozoa, Deuterostomia. D. P. gordon. 1: 271-297.

Götz, T., Hastie, G., Hatch, L. T., Raustein, O., Southall, B. L., Tasker, M., Thomsen, F., Campbell, J., Fredheim, B. (2009). "Overview of the impacts of anthropogenic underwater sound in the marine environment." OSPAR Biodiversity Series 441.

Gribben, P. E., Marshall, D. J., \& Steinberg, P. D. (2006). "Less inhibited with age? Larval age modifies responses to natural settlement inhibitors." Biofouling 22(2): 101-106.

Gruhl, A. (2008). "Muscular systems in gymnolaemate bryozoan larvae (Bryozoa: Gymnolaemata)." Zoomorphology 127(3): 143-159. 
Gruhl, A. (2009). "Serotonergic and FMRFamidergic nervous systems in gymnolaemate bryozoan larvae." Zoomorphology 128(2): 135-156.

Gruhl, A. (2010). "Neuromuscular system of the larva of Fredericella sultana (Bryozoa: Phylactolaemata)." Zoologischer Anzeiger-A Journal of Comparative Zoology 249(3): 139149.

Hamilton, S. L., Regetz, J., \& Warner, R. R. (2008). "Postsettlement survival linked to larval life in a marine fish." Proceedings of the National Academy of Sciences 105(5): 1561-1566.

Hawkins, A. D., Pembroke, A. E., \& Popper, A. N. (2015). "Information gaps in understanding the effects of noise on fishes and invertebrates." Reviews in Fish Biology and Fisheries 25(1): 39-64.

Hawkins, A. D., \& Popper, A. N. (2017). "A sound approach to assessing the impact of underwater noise on marine fishes and invertebrates." ICES Journal of Marine Science 74(3): 635-651.

Hayden, B. J., Inglis, G. J., \& Schiel, D. R. (2009). “Marine Invasions in New Zealand: A History of Complex Supply-Side Dynamics." Biological Invasions in Marine Ecosystems. G. Rilov and J. A. Crooks: 409-423.

Hearin, J., Hunsucker, K. Z., Swain, G., Gardner, H., Stephens, A., \& Lieberman, K. (2016). "Analysis of mechanical grooming at various frequencies on a large scale test panel coated with a fouling-release coating." Biofouling 32(5): 561-569.

Hearin, J., Hunsucker, K. Z., Swain, G., Stephens, A., Gardner, H., Lieberman, K., \& Harper, M. (2015). "Analysis of long-term mechanical grooming on large-scale test panels coated with an antifouling and a fouling-release coating." Biofouling 31(8): 625-638. 
Hewitt, C. L., Willing, J., Bauckham, A., Cassidy, A. M., Cox, C. M. S., Jones, L., \& Wotton, D. M. (2004). "New Zealand marine biosecurity: Delivering outcomes in a fluid environment." New Zealand Journal of Marine and Freshwater Research 38(3): 429-438.

Highsmith, R. C. (1982). "Induced Settlement and Metamorphosis of Sand Dollar (Dendraster Ecentricus) Larvae in Predator-Free sites: Adult Sand Dollar Beds." Ecology 63(2): 329-337.

Hopkins, G. A., \& Forrest, B. M. (2008). "Management options for hull fouling: an overview of risks posed by in-water cleaning." ICES Journal of Marine Science 65: (811-815).

Inglis, G., Floerl, O., \& Woods, C. (2012). "Scenarios of Vessel Biofouling Risk and their Management: An evaluation of options." M. o. A. a. Forestry, NIWA.

Iwata, H., Tanabe, S., Mizuno, T., \& Tatsukawa, R. (1997). "Bioaccumulation of butyltin compounds in marine mammals: the specific tissue distribution and composition." Applied Organometallic Chemistry 11(4): 257-264.

Jablonski, D., \& Lutz, R. A. (1983). "Larval ecology of marine benthic invertebrates: paleobiological implications." Biological Reviews 58(1): 21-89.

Jékely, G., Colombelli, J., Hausen, H., Guy, K., Stelzer, E., Nédélec, F., \& Arendt, D. (2008). "Mechanism of phototaxis in marine zooplankton." Nature 456(7220): 395-399.

Jellali, R., Campistron, I., Pasetto, P., Laguerre, A., Gohier, F., Hellio, C., Pilard, J-F., Mouget, J-L. (2013). "Antifouling activity of novel polyisoprene-based coatings made from photocurable natural rubber derived oligomers." Progress in Organic Coatings 76(9): 12031214.

Jung, C. A., \& Swearer, S. E. (2011). "Reactions of temperate reef fish larvae to boat sound." Aquatic Conservation: Marine and Freshwater Ecosystems 21(4): 389-396. 
Kaplan, M. B., \& Solomon, S. (2016). "A coming boom in commercial shipping? The potential for rapid growth of noise from commercial ships by 2030." Marine Policy 73: 119-121.

Karlsson, J., \& Eklund, B. (2004). "New biocide-free anti-fouling paints are toxic." Marine Pollution Bulletin 49: 456-464.

Karlsson, J., Ytreberg, E., \& Eklund, B. (2010). "Toxicity of anti-fouling paints for use on ships and leisure boats to non-target organisms representing three trophic levels." Environmental Pollution 158: 681-687.

Kauano, R. V., Roper, J. J., \& Rocha, R. M. (2017). "Small boats as vectors of marine invasion: experimental test of velocity and desiccation as limits." Marine Biology 1(164): 1-10.

Lacoste, E., \& Gaertner-Mazouni, N. (2015). "Biofouling impact on production and ecosystem functioning: a review for bivalve aquaculture." Reviews in Aquaculture 7: 187196.

Lacoursiere-Roussel, A., Forrest, B. M., Guichard, F., Piola, R. F., \& McKindsey, C.W. (2012). "Modeling biofouling from boat and source characteristics: a comparative study between Canada and New Zealand." Biological Invasions 14: 2301-2314.

Leis, J. M., \& Lockett, M. M. (2005). "Localization of reef sounds by settlement-stage larvae of coral-reef fishes (Pomacentridae)." Bulletin of Marine Science 76: 715-724.

Lillis, A., Eggleston, D.B., \& Bohnenstiehl, D. R. (2013). "Oyster Larvae Settle in Response to Habitat-Associated Underwater Sounds." PlosOne 8(10): 1-10.

Lindholdt, A., Dam-Johansen, K., Olsen, S. M., Yebra, D. M., \& Kiil, S. (2015). "Effects of biofouling development on drag forces of hull coatings for ocean-going ships: a review." Journal of Coatings Technology and Research 12(3): 415-444. 
Lugli, M. (2013). "Sand pile above the nest amplifies the sound emitted by the male sand goby." Environmental Biology of Fishes 96: 1003 - 1012.

MacAyeal, D., Okal, E., Aster, R., \& Bassis, J. (2008). "Seismic and hydroacoustic tremor generated by colliding icebergs." Journal of Geophysical Research: Earth Surface 113(3).

Maleb, L., Le-Clech, P., Vrouwenvelder, J.S., Ayoub, G.M., \& Saikaly, P. E. (2013). "Do biological strategies hold promise to biofouling control in MBRs?" Water Research 47: 54475463.

Mant, R. C., Morridge, G. D., \& Alderidge, D. C. (2011). "Biofouling by bryozoans, Cordylophora and sponges in UK water treatment works." Water science and technology 63(9): 1815-1822.

Mant, R. C., Morridge, G. D., \& Alderidge, D. C. (2013). "Control of the biofouling bryozoan, Plumatella repens, using pulsed chlorine treatment." International Journal of Environmental Science and Technology 10: 199-208.

Marshall, D. J., \& Keough, M. J. (2003). "Variation in the dispersal potential of non-feeding invertebrate larvae: the desperate larva hypothesis and larval size." Marine Ecology Progress Series 255: 145-153.

Matsumoto, H., Bohnenstiehl, D. R., Tournadre, J., Dziak, R. P., Haxel, J. H., Lau, T-KA., Fowler, M., Salo, S.A. (2014). "Antarctic icebergs: A significant natural ocean sound source in the Southern Hemisphere." Geochemistry, Geophysics, Geosystems 15: $3448-3458$.

McDonald, J. I., Wilkens, S. L., Stanley, J. A., \& Jeffs, A. G. (2014). "Vessel generator noise as a settlement cue for marine biofouling species." Biofouling 30(6): 741-749.

McEdward, L. R. (1997). "Reproductive strategies of marine benthic invertebrates revisited: facultative feeding by planktotrophic larvae." The American Naturalist 150(1): 48-72. 
McEdward, L. R. (2000). “Adaptive evolution of larvae and life cycles." Seminars in cell \& developmental biology, Elsevier.

Menze, S., Zitterbart, D. P., van Opzeeland, I., \& Boebel, O. (2017). "The influence of sea ice, wind speed and marine mammals on Southern Ocean ambient sound." Royal Society Open Science 4(160370): 1 - 20.

Metaxas, A., \& Saunders, M. (2009). "Quantifying the "bio-" components in biophysical models of larval transport in marine benthic invertebrates: advances and pitfalls." The Biological Bulletin 216(3): 257-272.

Miksis-Olds, J. L. (2016). "Global Trends in Ocean Noise." The Effects of Noise on Aquatic Life II, Springer: 713-718.

Montgomery, J. C., Jeffs, A., Simpson, S. D., Meekan, M., \& Tindle, C. (2006). "Sound as an orientation cue for the pelagic larvae of reef fishes and decapod crustaceans." Advances in marine biology 51: 143-196.

Myrberg, A. A. (1990). "The effects of man-made noise on the behavior of marine animals." Environment International 16(4-6): 575-586.

Nehring, S. (2001). "After the TBT Era: Alternative Anti-fouling Paints and their Ecological Risks." Senckenbergiana maritima 31(2): 341-351.

Neo, Y. Y., Seitz, J., Kastelein, R. A., Winter, H. V., Ten Cate, C., \& Slabbekoorn, H. (2016). "Noise Impact on European Sea Bass Behavior: Temporal Structure Matters." The Effects of Noise on Aquatic Life II, Springer: 763-766.

Ng, T. Y. T., \& Keough, M. J. (2003). "Delayed effects of larval exposure to Cu in the bryozoan Watersipora subtorquata." Marine Ecology Progress Series 257: 77-85. 
Nogata, Y., \& Kitano, Y. (2006). "Isocyano compounds as non-toxic antifoulants." Antifouling compounds: 87-104.

Nousek-McGregor, A. E., \& Mei, F. T. L. (2016). “Does noise from shipping and boat traffic affect predator vigilance in the European common hermit crab?" The Effects of Noise on Aquatic Life II, Springer: 767-774.

Parmentier, E., Berten, L., Rigo, P., Aubrun, F., Nedelec, S. L., Simpson, S. D., Lecchini, D. (2015). "The influence of various reef sounds on coral-fish larvae behaviour." Journal of Fish Biology 86: 1507-1518.

Pawlik, J. R. (1992). "Chemical ecology of the settlement of benthic marine invertebrates." Oceanography and Marine Biology - Annual Review 30: 273-335.

Pechenik, J. A. (2006). "Larval experience and latent effects-metamorphosis is not a new beginning." Integrative and Comparative Biology 46(3): 323-333.

Piola, R. F., \& Conwell, C. (2010). "Vessel biofouling as a vector for the introduction of nonindigenous marine species to New Zealand: Fishing vessels." M. o. A. a. Forestry, Cawthron Institute.

Piola, R. F., \& Johnston, E. L. (2006). "Differential resistance to extended copper exposure in four introduced bryozoans." Marine Ecology Progress Series 311: 103-114.

Piola, R. F., \& McDonald, J. I. (2012). "Marine biosecurity: The importance of awareness, support and cooperation in managing a successful incursion response." Marine Pollution Bulletin 64: 1766-1773.

Qian, P-Y., Xu, Y., \& Fusetani, N. (2010). "Natural products as antifouling compounds: recent progress and future perspectives." Biofouling 26(2): 223-234. 
Quick, N., Scott-Hayward, L., Sadykova, D., Nowacek, D., \& Read, A. (2017). "Effects of a scientific echo sounder on the behavior of short-finned pilot whales (Globicephala macrorhynchus)." Canadian Journal of Fisheries and Aquatic Sciences 74(5): 716-726.

Radford, A. N., Purser, J., Bruintjes, R., Voellmy, I.K., Everley, K. A., Wale, M.A., Holles, S., Simpson, S. D. (2016). "Beyond a simple effect: variable and changing responses to anthropogenic noise." The effects of noise on aquatic life II, Springer: 901-907.

Radford, C. A., Jeffs, A. G., \& Montgomery, J. C. (2007). "Directional swimming behavior by five species of crab postlarvae in response to reef sound." Bulletin of Marine Science 80(2): 369-378.

Reed, C. G. (1987). "The organization and isolation of the ciliary locomotory and sensory organs of marine bryozoan larvae." Oxford Press, New Delhi: 397-408.

Reed, C. G. (1988). "Organization of the nervous system and sensory organs in the larva of the marine bryozoan Bowerbankia gracilis (Ctenostomata: Vesiculariidae): functional significance of the apical disc and pyriform organ." Acta Zoologica 69(3): 177-194.

Reed, C. G. (1991). "Bryozoa". Reproduction of Marine Invertebrates. A. C. Giese, J. S. Pearse and V. B. Pearse. Pacific Grove, California, The Boxwood Press. 6: 85-245.

Reed, C. G. and R. A. Cloney (1982). "The larval morphology of the marine bryozoan Bowerbankia gracilis (Ctenostomata: Vesicularioidea)." Zoomorphology 100(1): 23-54.

Reed, C. G., Ninos, J. M., \& Woollacott, R. M. (1988). "Bryozoan larvae as mosaics of multifunctional ciliary fields: ultrastructure of the sensory organs of Bugula solonifera (Cheilostomata: Cellularioidea)." Journal of Morphology 197(2): 127-145.

Roche, R., Monnington, J., Newstead, R., Sambrook, K., Griffith, K., Holt, F., \& Jenkins, S. (2015). "Recreational vessels as a vector for marine non-natives: developing biosecurity 
measures and managing risk through an in-water encapsulation system." Hydrobiologia 750(1): 187.

Rosenhahn, A., Schilp, S., Kreuzer, H. J., \& Grunze, M. (2010). "The role of "inert" surface chemistry in marine biofouling prevention." Physical Chemistry Chemical Physics 12: 42754286.

Ruiz, G. M., Fofonoff, P. W., Steves, B. P., \& Carlton, J. T. (2015). "Invasion history and vector dynamics in coastal marine ecosystems: A North American perspective " Aquatic Ecosystem Health and Management: 299-311.

Sams, M. A., \& Keough, M. J. (2012). "Contrasting effects of variable species recruitment on marine sessile communities." Ecology 93(5): 1153-1163.

Sams, M. A., Warren-Myers, F., \& Keough, M. J. (2015). "Increased larval planktonic duration and post-recruitment competition influence survival and growth of the bryozoan Watersipora subtorquata." Marine Ecology Progress Series 531: 179-191.

Santagata, S. (2008A). "The morphology and evolutionary significance of the ciliary fields and musculature among marine bryozoan larvae." Journal of Morphology 269(3): 349-364.

Santagata, S. (2008B). "Evolutionary and structural diversification of the larval nervous system among marine bryozoans." The Biological Bulletin 215(1): 3-23.

Santagata, S., \& Zimmer, R. L. (2000). “Comparing Cell Patterns of Coronate Bryozoan Larvae with Fluorecent Probes." 11th International Bryozoology Association Conference.

Schultz, M. P., Bendick, J. A., Holm, E. R., \& Hertel, W. M. (2011). "Economic impact of biofouling on a naval surface ship." Biofouling 27(1): 87-98.

Seed, R., \& Hughes, R. (1992). "Reproductive strategies of epialgal bryozoans." Invertebrate Reproduction \& Development 22(1-3): 291-300. 
Selim, M., Shenashen, M., El-Safty, S. A., Higazy, S., Isago, H., \& Elmarakbi, A. (2017). "Recent progress in marine foul-release polymeric nanocomposite coatings." Progress in Materials Science.

Sievers, M., Dempster, T., Fitridge, I., \& Keough, M. J. (2014). "Monitoring biofouling communities could reduce impacts to mussel aquaculture by allowing synchronisation of husbandry techniques with peaks in settlement." Biofouling 30(2): 203-212.

Simpson, S. D., Meekan, M. G., Jeffs, A., Montgomery, J. C, \& McMauley, R. D. (2008). "Settlement-stage coral reef fish prefer the higher-frequency invertebrate-generated audible component of reef noise." Animal Behaviour 75(6).

Simpson, S. D., Radford, A. N., Holles, S., Ferarri, M. C., Chivers, D. P., McCormick, M, I., \& Meekan, M. G. (2016). "Small-boat noise impacts natural settlement behavior of coral reef fish larvae." The Effects of Noise on Aquatic Life II, Springer: 1041-1048.

Širović, A., Hildebrand, J. A., \& McDonald, M. A. (2016). "Ocean ambient sound south of Bermuda and Panama Canal traffic." The Journal of the Acoustical Society of America 139(5): $2417-2423$.

Stanley, J. A., Radford, C. A., \& Jeffs, A. G. (2012). “Effects of underwater noise on larval settlement." Springer Science + Business Media, LLC 2012.

Stanley, J. A., Wilkens, S., McDonald, J. I., \& Jeffs, A. G. (2016). "Vessel noise promotes hull fouling." The Effects of Noise on Aquatic Life II, Springer: 1097-1104.

Stanley, J. A., Wilkens, S. L., \& Jeffs, A. G. (2014). "Fouling in your own nest: vessel noise increases biofouling." Biofouling 30(7): 837-844.

Tribou, M., \& Swain, G. (2010). "The use of proactive in-water grooming to improve the performance of ship hull antifouling coatings." Biofouling 26(1): 47-56. 
Tribou, M., Swain, G. (2015). "Grooming using rotating brushes as a proactive method to control ship hull fouling." Biofouling 31(4): 309-319.

Tribou, M., Swain, G. (2017). "The effects of grooming on a copper ablative coating: a six year study." Biofouling 33(6): 494-504.

Turner, A. (2010). "Marine pollution from antifouling paint particles." Marine Pollution Bulletin 60(2): 159-171.

Venkatesan, R., Senthilkumar, P., Vedachalam, N., \& Murugesh, P. (2017). "Biofouling and its effects in sensor mounted moored observatory system in Northern Indian Ocean." International Biodeterioration \& Biodegradation 116: 198-204.

Vermeij, M. J. A., Merhaver, K. L., Huijbers, C. M., Nagelkerken, I., \& Simpson, S. D. (2010). "Coral larvae move toward reef sounds." PlosOne 5(5): 1-4.

Viera, L. M., Jones, M. S., \& Taylor, P. D. (2014). "The identity of the invasive fouling bryozoan Watersipora subtorquata (d'Orbigny) and some other congeneric species." Zootaxa 3857(2): 151-182.

von der Meden, C. E., Cole, V. J., \& McQuaid, C. D. (2015). "Do the threats of predation and competition alter larval behaviour and selectivity at settlement under field conditions?" Journal of Experimental Marine Biology and Ecology 471: 240-246.

Voulvoulis, N., Scrimshaw, M., \& Lester, J. (1999). "Alternative antifouling biocides." Applied Organometallic Chemistry 13(3): 135-143.

Vrouwenvelder, J. S., Kruithof, J. C., \& Loosdrecht, M. V. (2010). "Integrated approach for biofouling control." Water science and technology 62(11): 2477-2490. 
Waite, R., Beveridge, M., Brummett, R., Castine, S., Chaiyawannakarn, N., Kaushik, S., Mungkung, R., Nawapakpilai, S., Phillips, M. (2014). "Improving Productivity and Environmental Performance of Aquaculture." Working Paper, Installment 5 of Creating a Sustainable Food Future. 2017, from http://www.worldresourcesreport.org.

Wendt, D. E., \& Woolacott, R. M. (1999). "Ontogenies of Phototactic Behavior and Metamorphic Competence in Larvae of Three Species of Bugula (Bryozoa)." Invertebrate Biology 118(1): 75-84.

Wenz, G. (1969). "Low-frequency deep-water ambient noise along the Pacific Coast of the United States." US Navy Journal Underwater Acoustics 19: 423-444.

White, J. W., Morgan, S. G., \& Fisher, J. L. (2014). "Planktonic larval mortality rates are lower than widely expected." Ecology 95(12): 3344-3353.

Wilkens, S. L., Stanley, J. A., \& Jeffs, A. G. (2012). "Induction of settlement in mussel (Perna canaliculus) larvae by vessel noise." Biofouling 28(1): 65-72.

Wisely, B. (1958). "The settling and some experimental reactions of a bryozoan larva, Watersipora cucullata (Busk)." Australian Journal Marine and Freshwater Research 9(3): 362-371.

World Bank (2013). Fish To 2030: Prospects for Fisheries and Aquaculture. Agriculture and environmental services discussion paper; no. 3. Retrieved from Washington, DC. (C) World Bank: https://openknow;edge.worldbank.org/handle/10986/17579.

Yebra, D. M., Kiil, S., \& Dam-Johansen, K. (2004). "Antifouling technology-past, present and future steps towards efficient and environmentally friendly antifouling coatings." Progress in Organic Coatings 50(2): 75-104.

Yebra, D. M., \& Català, P. (2011). "Coatings \& Linings-Redefining Antifouling Coating Technology-Part 2." Materials Performance 50(5): 40. 
Zhang, X., Brodus, D., Hollimon, V., \& Hu, H. (2017). "A brief review of recent developments in the designs that prevent bio-fouling on silicon and silicon-based materials." Chemistry Central Journal 11(1): 18.

Zimmer, R. L. and R. M. Woollacott (1989A). "Intercoronal cell complex of larvae of the bryozon Watersipora arcuata (cheilostomata: Ascophora)." Journal of Morphology 199(2): 151-164.

Zimmer, R. L., \& Woolacott, R. M. (1989B). "Larval Morphology of the Bryozoan Watersipora arcuata (Cheilostomata: Ascophora)." Journal of Morphology 199: 125-150.

Zimmer, R. L. and R. M. Woollacott (1993). "Anatomy of the larva of Amathia vidovici (Bryozoa: Ctenostomata) and phylogenetic significance of the vesiculariform larva." Journal of Morphology 215(1): 1-29. 
Appendix A: Unused SEM images of $W$. subatra larvae
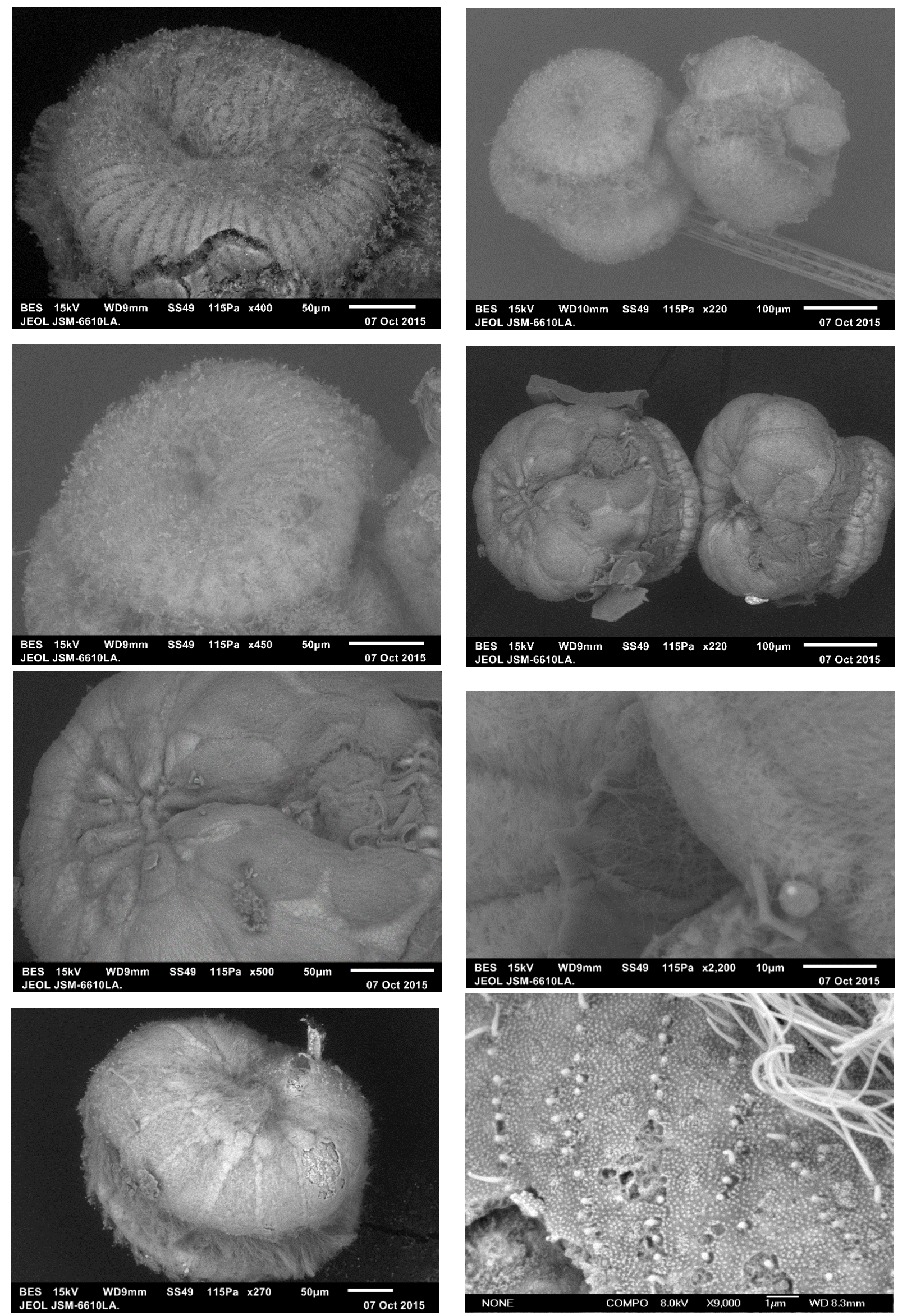

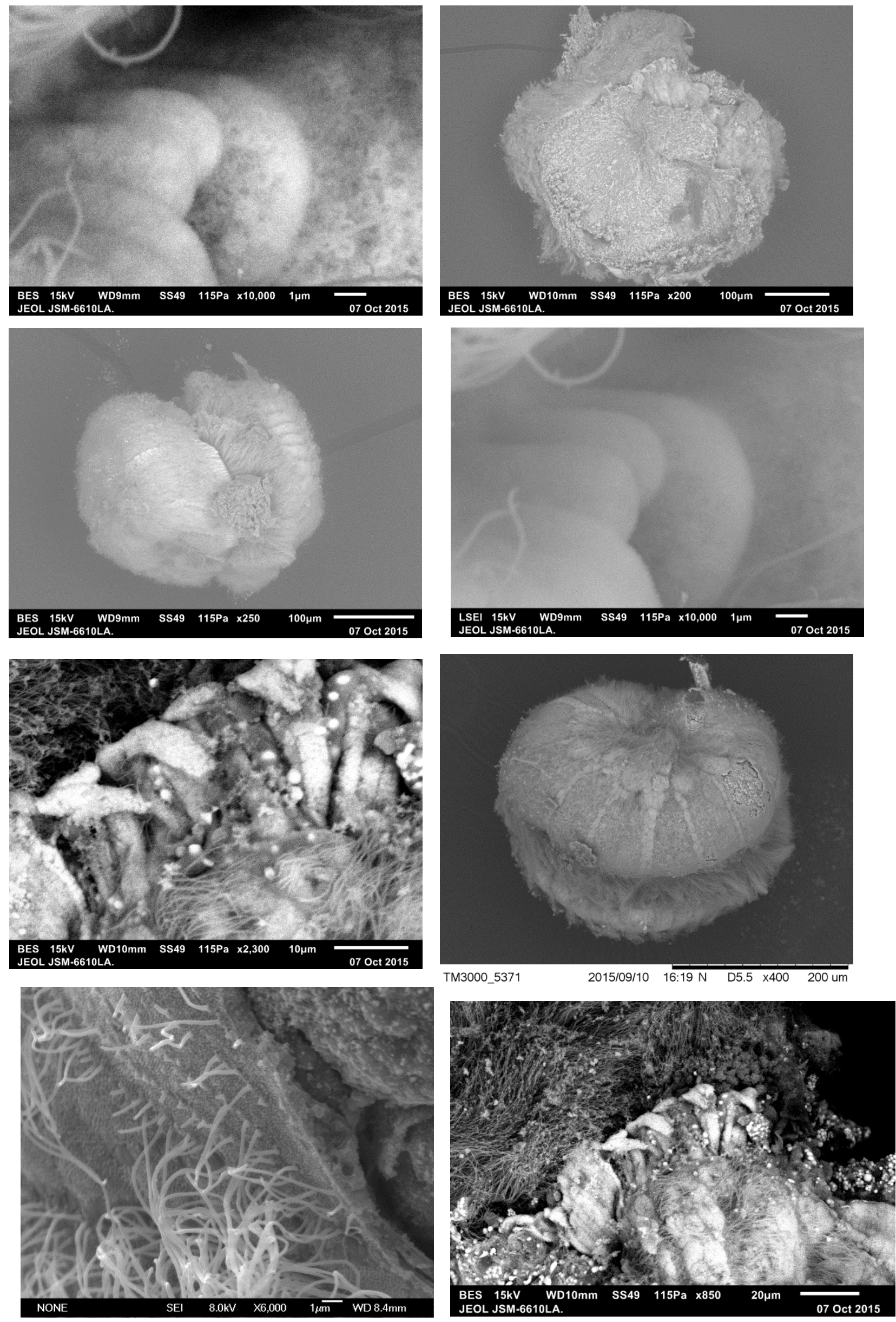

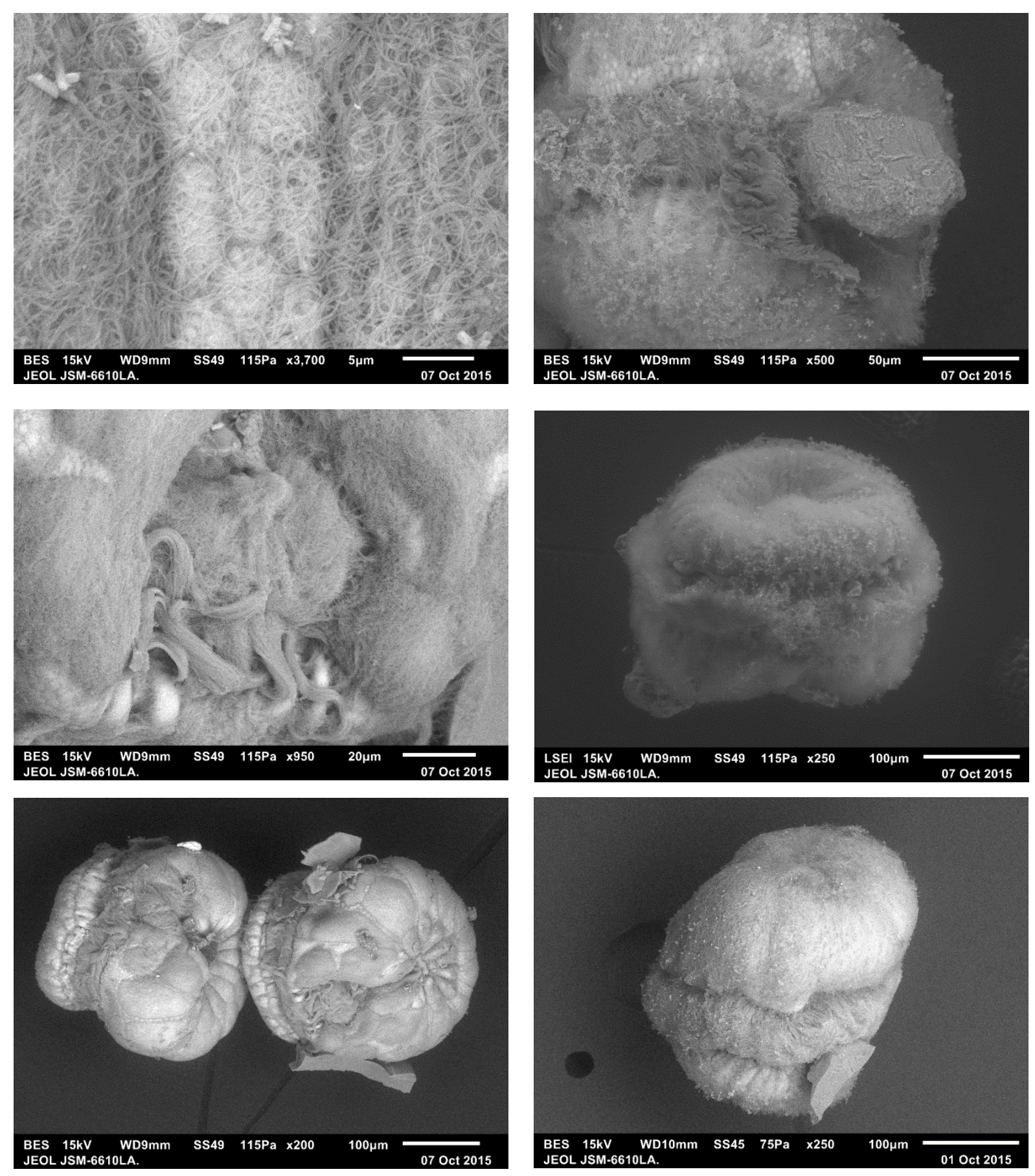


\section{Appendix B: Graphs and R output}
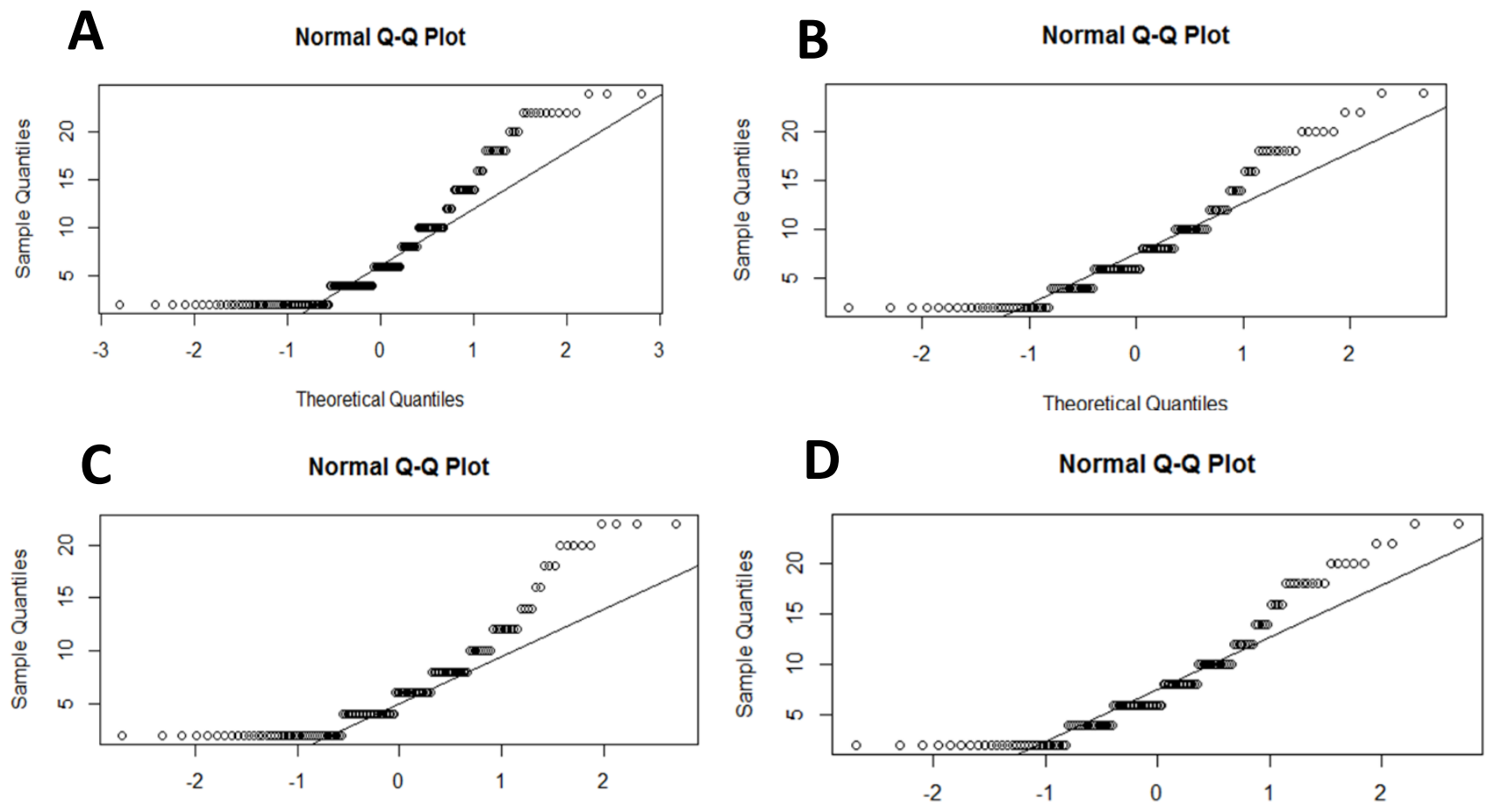

E

Normal Q-Q Plot

Theoretical Quantiles

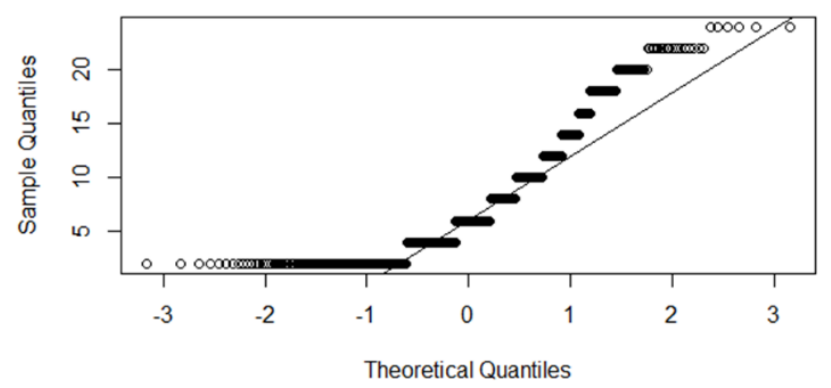

Figure $\mathbf{A} 1$ Normal $Q-Q$ plots for the data in each treatment group and the pooled data set. $\mathbf{A}: Q-Q$ plot for the silent control data; $\mathbf{B}: Q-Q$ plot for treatment one data; C: Q-Q plot for treatment two data; D: Q-Q plot for treatment three data; E: Q-Q plot for pooled data set

\section{Data summary for linear mixed-effects model from R-studio:}

\begin{tabular}{|c|c|c|c|c|c|c|c|}
\hline \multicolumn{2}{|c|}{$\begin{array}{c}\text { summary (pooled) } \\
\text { waterbath }\end{array}$} & \multicolumn{2}{|c|}{ BryozoanID } & \multicolumn{2}{|c|}{ Treatment } & \multirow[t]{2}{*}{ settled } & TimeofsettlementHOU \\
\hline RS & & & & & & & \\
\hline w1C & $: 24$ & т10т2W3В863: & 1 & CON & $L: 213$ & D: & $: 2.00$ \\
\hline W1E & $: 24$ & Т10T2W3B864: & 1 & T1 & $: 165$ & $\mathrm{~N}: 80$ & 1st Qu.: 2.00 \\
\hline W1F & $: 24$ & Т10T2W3B865: & 1 & T2 & :167 & $Y: 629$ & Median : 6.00 \\
\hline W2A & $: 24$ & т10т2W3В866: & 1 & T3 & :166 & & Mean \\
\hline W2B & $: 24$ & Т10T2W3B867: & 1 & & & & 3rd Qu.: 10.00 \\
\hline W2C & $\begin{array}{l}: 24 \\
: 567\end{array}$ & T10T2W3B868: & $\begin{array}{r}1 \\
705\end{array}$ & & & & $\begin{array}{ll}\text { Max. } & : 24.00\end{array}$ \\
\hline
\end{tabular}


$\mathrm{R}$ code for linear mixed-effects model using $7 \mathrm{me} 4$ package using the REML criterion to fit $t$ he model:

pooled.model $=1$ mer $($ TimeofsettlementHouRs $\sim$ Treatment $+(1 \mid$ wate rbath $)+(1 \mid$ settled $)$, data=pooled $)$

Data output for about R-code using the REML criterion to fit the model:

Linear mixed model fit by REML ['1merMod']

Formula: TimeofsettlementHouRS $\sim$ Treatment $+(1 \mid$ waterbath $)+$ (1 | Settled)

Data: pooled

REML criterion at convergence: 3964.5

Scaled residuals:

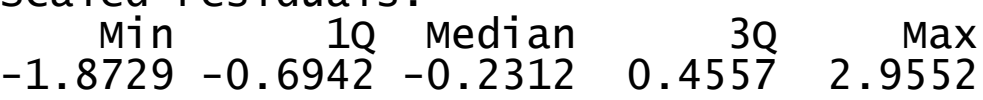

Random effects:

$\begin{array}{llll}\text { Groups } & \text { Name } & \text { Variance } & \text { Std.Dev. } \\ \text { waterbath } & \text { (Intercept) } & 5.683 \mathrm{e}+00 & 2.384 \mathrm{e}+00 \\ \text { Settled } & \text { (Intercept) } & 1.731 \mathrm{e}-12 & 1.316 \mathrm{e}-06 \\ \text { Residua1 } & & 2.955 \mathrm{e}+01 & 5.436 \mathrm{e}+00\end{array}$

Number of obs: 631, groups: waterbath, 30; settled, 2

Fixed effects:

$\begin{array}{lrrr} & \text { Estimate } & \text { Std. Error } & \text { value } \\ \text { (Intercept) } & 7.9772 & 0.8854 & 9.010 \\ \text { TreatmentT1 } & 0.3535 & 1.3462 & 0.263 \\ \text { TreatmentT2 } & -1.0231 & 1.3402 & -0.763 \\ \text { TreatmentT3 } & -0.3815 & 1.3414 & -0.284\end{array}$

Correlation of Fixed Effects:

(Intr) TrtmT1 TrtmT2

TreatmentT1 -0.658

TreatmentT2 -0.661

TreatmentT3 -0.660

0.434

0.4340 .436

$R$ code for linear mixed-effects model using 7 me4 package using maximum likelihood to fit the model:

pooled.mode1 = 1mer (TimeofSettlementHouRS $\sim$ Treatment $+(1 \mid$ wate rbath $)+(1 \mid$ settled $)$, data $=$ pooled, REML = FALSE) 
Data output for about R-code using maximum likelihood fit the model:

Linear mixed model fit by maximum likelihood ['TmerMod'] Formula: TimeofsettlementHouRS $\sim$ Treatment $+(1 \mid$ waterbath $)+$ (1 | Settled)

Data: pooled

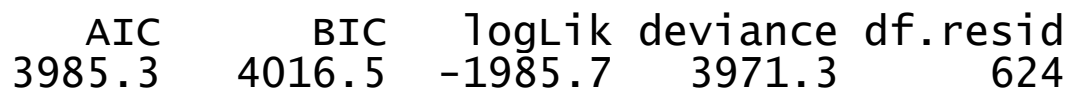

Scaled residuals:
Min
10 Median
$3 Q$
$\operatorname{Max}$
$-1.8453-0.7063-0.2368$
$0.4694 \quad 2.9417$

Random effects:

$\begin{array}{llll}\text { Groups } & \text { Name } & \text { Variance } & \text { Std.Dev. } \\ \text { Waterbath } & \text { (Intercept) } & 4.74 & 2.177 \\ \text { Settled } & \text { (Intercept) } & 0.00 & 0.000 \\ \text { Residual } & & 29.55 & 5.436\end{array}$

Number of obs: 631, groups: waterbath, 30; sett1ed, 2

Fixed effects:

$\begin{array}{lrrr} & \text { Estimate std. Error } t \text { value } \\ \text { (Intercept) } & 7.9710 & 0.8240 & 9.673 \\ \text { TreatmentT1 } & 0.3563 & 1.2541 & 0.284 \\ \text { TreatmentT2 } & -1.0214 & 1.2476 & -0.819 \\ \text { TreatmentT3 } & -0.3795 & 1.2489 & -0.304\end{array}$

Correlation of Fixed Effects:

(Intr) TrtmT1 TrtmT2

TreatmentT1 -0.657

TreatmentT2 $-0.660 \quad 0.434$

TreatmentT3 $-0.660 \quad 0.434 \quad 0.436$

$R$ code for calculating the $p$-value of the values in the mixed-effects model:

$\operatorname{pt}(q, d f)$

where $q$ is the observed test statistic, and df the degrees of freedom ( $n-1)$ 